This is a preprint of an article published by Elsevier . The final version of Noushin Rajabalinia, Shaghayegh Hamzehlou, Jose R. Leiza, José M. Asua, Experimental validation of a mathematical model for the evolution of the particle morphology of waterborne polymer-polymer hybrids: Paving the way to the design and implementation of optimal polymerization strategies, Chemical Engineering Journal, (2019), 363, 259-269 is available at https://doi.org/10.1016/j.cej.2019.01.140

\title{
Experimental validation of a mathematical model for the evolution of the particle morphology of waterborne polymer-polymer hybrids: paving the way
}

\section{to the design and implementation of optimal polymerization strategies}

\author{
Noushin Rajabalinia, Shaghayegh Hamzehlou, Jose R. Leiza, José M. Asua* \\ POLYMAT, Kimika Aplikatua saila, Kimika Zientzien Fakultatea, University of the Basque \\ Country UPV/EHU, Joxe Mari Korta Zentroa, Tolosa Hiribidea 72, 20018, Donostia-San \\ Sebastián, Spain
}

\begin{abstract}
:
Polymer-polymer composite nanoparticles allow both the improvement of the performance in stablished applications of waterborne polymer dispersions and targeting new applications that are out of reach of currently available products. The performance of these materials is determined by the particle morphology. To open the way to process optimization and on-line control of the particle morphology, the capability of the recently developed model to predict the evolution of the particle morphology during seeded semibatch emulsion polymerization process was evaluated. Structured polymer particles were synthesized by copolymerization of styrene and butyl acrylate (St-BA) on methyl methacrylate and butyl acrylate (MMA-BA) copolymer seeds of different Tgs. The model captured well the effect of process variables on the evolution of the particle morphology, opening the way to the design and implementation of optimal strategies.
\end{abstract}

Keywords: Particle morphology evolution, hybrid particles, emulsion polymerization, modeling 


\section{Introduction}

Multiphase polymeric nanoparticles that synergistically combine the properties of their constituents present enhanced properties and display new functionalities. This opens a wide range of applications for waterborne dispersions including anticorrosive[1,2], superhydrophobic[3] and anti-fungal coatings[4], switchable adhesives[5], photo-switchable fluorescent particles[6], energy storage[7,8], gene and drug delivery[9-11], anticounterfeiting[12] and LEDs[13]. The production of these particles with defined morphology is of great interest, as it is recognized that application properties strongly depend on the morphology of the synthesized structured latex[14,15].

The most common method to synthesize polymer-polymer composite particles is seeded semibatch emulsion polymerization. During the polymerization, the particle morphology forms as a result of phase separation of the second stage polymer that is usually incompatible with the polymer in the seed. Thermodynamics defines the equilibrium morphology, which corresponds to the minimum surface energy, and in a two-phase polymer-polymer system the morphology can be either core-shell[16,17], inverted core-shell[18,19] or hemispherical[20-22]. Kinetically metastable morphologies (non-equilibrium) are reached as a result of hindered movement of the clusters due to the high internal viscosity of the particles.[14,23-29]. The internal viscosity depends on the molecular weight, crosslinking density and glass transition temperature ( $\mathrm{Tg}$ ) of the seed polymer, the polymerization temperature, and the amount of free monomer in the reactor (monomer acts as plasticizer). 
The effect of the internal viscosity is reinforced when the second stage polymer is produced in a position that is far from where it will be under equilibrium conditions. The position where the polymer is formed depends on the radical and monomer concentration profiles in the particles. Often flat concentration profiles of monomer and radicals within the polymer particles are considered in emulsion polymerization[30-35]. However, in processes carried out at temperatures lower than the $\mathrm{Tg}$ of the seed and under severe starved conditions, the concentration of monomer near the particle surface may be greater than in the interior of the particles[36,37]. On the other hand, Grancio and Williams[38] proposed the existence of a decreasing concentration profile of radicals within the polymer particles when water soluble initiators were used. The rationale behind this is that the radicals entering into the particle have a hydrophilic segment (many contain a charged inorganic moiety) that is anchored to the surface of the particle and therefore their movement towards the center of the particle is restricted.[39] Computer simulations show that decreasing radical concentration profiles can also be produced when hydrophobic radical (e.g. tert-butoxy radicals) enter the particles from the aqueous phase (see Supporting Information). In this case, the concentration profile is the result of the slow diffusion of the entering radical due to its rapid growth. It was early recognized that this profile could affect particle morphology[40] and this has been confirmed later. [41]

The effect of the decreasing profiles of radical concentration is expected to be stronger for inverted core-shell equilibrium morphologies where the second stage polymer is substantially more hydrophobic than the seed. In this case, the radical concentration profile restricts the formation of the second stage polymer to a region close to the surface of the particle and hence the hydrophobic polymer is produced far from the equilibrium position (center of the particle). 
Sundberg and coworkers[37,42-46] have published a series of articles where the effect of the variables discussed above on particle morphology is clearly shown. Thus, the effect of the $\mathrm{Tg}$ of the seed polymer was studied using seeds of PMMA/PMA with Tgs ranging from 52 to $98^{\circ} \mathrm{C}$ and PS as the second stage polymer. It was shown that when the Tg of the seed was higher than the reaction temperature, the polystyrene stayed on the surface of the particles and by decreasing the $\mathrm{Tg}$ of the seed to $52^{\circ} \mathrm{C}$, the polystyrene clusters penetrated into the matrix. However, even at such low $\mathrm{Tg}$ of the seed, the inverted core-shell equilibrium morphology was not obtained.[43] The effect of the initiator end group (charged vs. uncharged) was studied finding that under most conditions, the type of end group was not the dominant effect in determining the particle morphology.[44] Chain transfer agents can make the radical concentration profile flatter allowing penetration of the radicals to the interior of the particles and therefore enhancing the distribution of the second-stage polymer throughout the latex particles[47].

In some cases, particle morphologies far from equilibrium are desired. This is the case of multilobed particles that can be used as thickeners[48]. A way to do this is by using a crosslinked seed[49], but the crosslinked polymer may interfere with application properties. Blenner et al. [50] outlined the key factors for achieving multi-lobed polymer composite latexes with a noncrosslinked seed. The first criterion is that the radicals should not penetrate in the seed and the second stage polymer should be more hydrophobic than the seed. If these conditions are fulfilled, the particle morphology is controlled by the difference between the reaction temperature and the Tgs of the seed and second phase polymer. A guiding morphological map is provided. The map shows that if the second stage polymer is soft at the reaction temperature, the lobes can move and coagulate between themselves to decrease the surface energy leading to the formation of welldefined lobes. On the other hand, a glassy second stage polymer stays were it forms and a shell 
of the second stage polymer with a rough surface is formed. Stubbs et al. showed that penetration of oligomeric radicals and phase separation followed by phase domain consolidation is kinetically controlling the morphology. Occluded non-equilibrium morphologies were obtained in the case that the penetration of the radicals and phase separation were possible and the separated phase domains were partially rearranged via coalescence.[51]

The works discussed above provide a nice qualitative guide for the effect of the operation variables on the final particle morphology. However, this may not be enough to successfully produce products with target morphology in an industrial process. Emulsion polymerization is an extremely competitive business where reaching the desired morphology does not guarantee success as other aspects as operation cost, safety and process time are critical. It has been already demonstrated in silico [52] that the optimal emulsion polymerization process to achieve the desired particle morphology taking into account aspects as equipment limitations, safety and process time is a complex strategy that is unlikely that can be designed only using the guide mentioned above. Even if a suboptimal strategy is obtained based on extensive experimental work with the help of the qualitative guide, the practical implementation will be restricted to open loop control, which cannot cope with unexpected uncertainties often encountered in real practice. Close loop control would be preferable, but there are no devices available for on-line monitoring of the particle morphology and particle morphology is not observable from other online available measurements.

Both process optimization and close-loop control will be possible if a mathematical model for the evolution of the particle morphology is available. The model can be directly used in optimization algorithms and as a "soft" sensor in on-line monitoring. A model for the development of the morphology of composite particles has been recently proposed[53] and has 
been validated for polymer-inorganic materials[54], but its performance in polymer-polymer systems remains to be demonstrated.

In an attempt to pave the way to process optimization and on-line control, this work aims at evaluating the capability of the model to describe the evolution of the particle morphology during seeded semibatch emulsion polymerization, which is the most widely used process for the polymerization of waterborne polymer-polymer hybrids[55]. The evolution of the particle morphology during the copolymerization of styrene (S) and butyl acrylate (BA) on methyl methacrylate (MMA)-BA seeds of different Tgs was determined by Cryo and conventional TEM. The capability of the model was checked by fitting the experimental data.

\section{Experimental section}

\subsection{Material}

Methyl methacrylate (MMA) (Quimidroga), butyl acrylate (BA) (Quimidroga), styrene (S) (Quimidroga), acrylic acid (AA) (Aldrich) and acrylamide (AM) (Aldrich) were used as received. Sodium persulfate (NaPS) (Fluka), tert-Butyl hydroperoxide (TBHP) (Aldrich) and acetone bisulfate (ACBS) (BASF, Germany) were used as initiators. Sodium lauryl sulfate (SLS) (Aldrich) and Emulan-OG (BASF, Germany) were used as ionic and non-ionic emulsifiers, respectively. Deionized water (DI-water) was used in the emulsions and hydroquinone (Aldrich) was used for stopping the reaction in the samples withdrawn from the reactor. Ethanol (Aldrich) was used as internal standard in gas chromatography (GC).

\subsection{Synthesis of the latexes}

Table 1 summarizes the latexes synthesized. The composite polymer particles were synthesized by seeded semi-batch emulsion copolymerization using seeds with different Tgs. The seeds were 
prepared using the formulation in Table 2. The theoretical Tgs given by the Flory-Fox equation[56] were $\operatorname{Tg}_{\text {seed } 1}=90{ }^{\circ} \mathrm{C}, \operatorname{Tg}_{\text {seed } 2}=60^{\circ} \mathrm{C}$ and $\operatorname{Tg}_{\text {seed } 3}=40{ }^{\circ} \mathrm{C}$. A one liter glass reactor with an anchor stirrer $(160 \mathrm{rpm})$ was charged with $175 \mathrm{gr}$ deionized water and heated to $80^{\circ} \mathrm{C}$. Then, 22.2 gr pre-emulsion (water, surfactants and monomers) and 2.5 gr initiator solution were injected to the reactor and polymerized for 15 minutes. The process was continued by preemulsion feeding with the feed rate of $1.9 \mathrm{~g} / \mathrm{min}$ in the first 15 minutes and $3 \mathrm{~g} / \mathrm{min}$ in the next 75 minutes. The initiator solution was fed at constant rate during 90 minutes. Finally the latex was allowed to react batchwise for one hour to eliminate the unreacted monomers. The whole process was carried out under nitrogen. The final solids content of the seeds was $38.5 \mathrm{wt} \%$.

Table 1- Summary of the composite latexes synthesized.

\begin{tabular}{|c|c|c|c|c|c|c|}
\hline Case & \multicolumn{2}{|c|}{ Monomer composition } & $\begin{array}{l}\text { wt } \% \text { (in } \\
\text { a phase) }\end{array}$ & $\begin{array}{c}\text { Estimated } \\
\mathrm{T}_{\mathrm{g}}\left({ }^{\circ} \mathrm{C}\right)\end{array}$ & Initiator & $\begin{array}{l}\text { Reaction } \\
\text { temperature } \\
\left({ }^{\circ} \mathrm{C}\right)\end{array}$ \\
\hline \multirow{2}{*}{1} & Seed & MMA/BA/AA/AM & $88 / 10 / 1 / 1$ & 90 & $\mathrm{NaPS}$ & 80 \\
\hline & $2^{\text {nd }}$ stage & $\mathrm{St} / \mathrm{BA} / \mathrm{AA} / \mathrm{AM}$ & $67 / 31 / 1 / 1$ & 40 & $\mathrm{TBHP}+\mathrm{ACBS}$ & 80 \\
\hline \multirow{2}{*}{2} & Seed & MMA/BA/AA/AM & $75 / 23 / 1 / 1$ & 60 & $\mathrm{NaPS}$ & 80 \\
\hline & $2^{\text {nd }}$ stage & St/BA/AA/AM & $67 / 31 / 1 / 1$ & 40 & $\mathrm{TBHP}+\mathrm{ACBS}$ & 80 \\
\hline \multirow{2}{*}{3} & Seed & MMA/BA/AA/AM & $64 / 34 / 1 / 1$ & 40 & $\mathrm{NaPS}$ & 80 \\
\hline & $2^{\text {nd }}$ stage & St/BA/AA/AM & $67 / 31 / 1 / 1$ & 40 & $\mathrm{TBHP}+\mathrm{ACBS}$ & 80 \\
\hline
\end{tabular}

Table 2. Formulation used to synthesize the seeds. Reaction temperature: $80^{\circ} \mathrm{C}$.

\begin{tabular}{|c|c|c|c|c|c|c|c|}
\hline \multirow{2}{*}{ Material (g) } & \multicolumn{3}{|c|}{ Initial load } & \multicolumn{4}{c|}{ Feeds } \\
\cline { 2 - 8 } & \multicolumn{3}{|c|}{} & \multicolumn{3}{c|}{ Pre-emulsion } & $\begin{array}{c}\text { Initiator } \\
\text { solution }\end{array}$ \\
\cline { 2 - 8 } & Seed 1 & Seed 2 & Seed 3 & Seed 1 & Seed 2 & Seed 3 & \\
\hline DI-water & $175+8$ & $175+8$ & $175+8$ & 91.6 & 91.6 & 91.6 & \\
\hline Emulan OG & 0.1 & 0.1 & 0.1 & 1.6 & 1.6 & 1.6 & \\
\hline SDS & 0.1 & 0.1 & 0.1 & 1.6 & 1.6 & 1.6 & \\
\hline AM & 0.1 & 0.1 & 0.1 & 1.6 & 1.6 & 1.6 & \\
\hline AA & 0.1 & 0.1 & 0.1 & 1.6 & 1.6 & 1.6 & \\
\hline MMA & 12.3 & 10.5 & 9.0 & 141.7 & 120.8 & 103.0 & \\
\hline BA & 1.4 & 3.2 & 4.8 & 16.1 & 37.0 & 54.7 & \\
\hline
\end{tabular}




\begin{tabular}{|c|c|c|c|c|c|c|}
\hline $\begin{array}{c}\text { NaPS solution } \\
\text {,7wt\% }\end{array}$ & 2.5 & 2.5 & 2.5 & & & \\
\hline
\end{tabular}

The formulation used in the seeded semi-batch emulsion copolymerization is given in Table 3 . The expected $\mathrm{Tg}$ of the second stage polymer was $40{ }^{\circ} \mathrm{C} .1 \mathrm{wt} \%$ of both $\mathrm{AA}$ and $\mathrm{AM}$ was included in the formulation of the seed and second stage polymer to improve the colloidal stability of the latexes. Relatively large final diameter of the composite latexes (250-300 nm) were targeted to facilitate the morphology characterization and to emphasize the kinetic effects during the evolution of the particle morphology. The polymerizations were carried out in the glass reactor used to prepare the seeds. The reactor was loaded with the seed and heated to $80^{\circ} \mathrm{C}$. TBHP solution was added to the reactor as a shot and then the pre-emulsion and the aqueous solutions of ACBS were fed during 90 minutes. After that, the unreacted monomers were removed by post-polymerization adding solution of TBHP and feeding aqueous solutions of ACBS for two hours. The whole process was carried out at $80^{\circ} \mathrm{C}$ under nitrogen. The final solids content was $47 \mathrm{wt} \%$ and coagulum free latexes were obtained.

Table 3. Formulation used for the seeded semi-batch emulsion copolymerization.

\begin{tabular}{|c|c|c|c|c|}
\hline Material (g) & $\begin{array}{c}\text { Initial } \\
\text { load }\end{array}$ & Pre-emulsion & $\begin{array}{c}\text { Initiator solutions } \\
\text { (Main polymerization) }\end{array}$ & $\begin{array}{c}\text { Initiator solutions } \\
\text { (Post polymerization) }\end{array}$ \\
\hline Seed & 465.6 & & & \\
\hline DI-water & & 99.4 & & \\
\hline Emulan OG & & 1.75 & & \\
\hline SDS & & 1.75 & & \\
\hline AM & & 1.75 & & \\
\hline AA & & 1.75 & & \\
\hline BA & & 54.25 & & \\
\hline S & & 117.25 & & 3.8 \\
\hline TBHP solution, $24 \mathrm{wt} \%$ & & & & \\
\hline ACBS solution, $13.1 \mathrm{wt} \%$ & & & & \\
\hline TBHP solution, $10 \mathrm{wt} \%$ & & & & \\
\hline
\end{tabular}




\subsection{Characterization}

The instantaneous conversion of samples withdrawn during the second stage polymerization was measured by gas chromatography (GC), using ethanol as internal standard. A GC apparatus (HP 6890 series) equipped with a HP 7694E headspace sampler and a BP 20 capillary column was used.

Particle sizes were measured by dynamic light scattering (DLS) using a Zetasizer Nano Series (Malvern Instrument). For the analysis the latex was diluted in DI-water to $0.005 \mathrm{wt} \%$. The reported average particle size values represent an average of three repeated measurements.

Transmission electron microscopy (TEM) was carried out with a Tecnai ${ }^{\mathrm{TM}}$ G2 20 Twin device at $200 \mathrm{kV}$ (FEI Electron Microscopes). The latexes were diluted with deionized water up to 0.05 $\mathrm{wt} \%$ solids content, one drop of the dilution was placed on carbon coated copper grid and dried at ambient temperature. TEM samples stained with $\mathrm{RuO}_{4}$ vapor for 1 hour to increase the contrast of the images. Particle morphology was also determined by Cryo-TEM and for the preparation of the samples one drop of the sample $(\sim 3 \mu \mathrm{l})$ was deposited in a copper grid (300 mesh, R QUANTIFOIL ${ }^{\circ}$ R 2/2 EMS, Hat-field, PA, USA, hydrophilized by glow-discharged treatment just prior to use) within the environmental chamber of a FEI Vitrobot Mark IV (Eindhoven, The Netherlands) and the excess liquid was blotted away. The sample was introduced into liquid nitrogen and transferred to a Single Tilt Cryo-Holder. The Cryo-Holder was previously prepared by 655 Turbo Pumping Station to maintain the sample below $-170^{\circ} \mathrm{C}$ and to minimize the thermal derive. The reason for using these two techniques is that they are complementary. Cryo-TEM gives a good representation of the topography of the surface of the particles whereas TEM of stained samples provides better contrast between phases and therefore a better idea of the particle morphology. 
Environmental Scanning Electron Microscopy (ESEM) images were obtained in a Quanta 250 FEG ESEM (FEI, Netherlands) equipped with a Peltier cooling stage and a gaseous secondary electron detector [57] using the conditions reported by Gonzalez-Matheus et al.[58]. The temperature increased from $0^{\circ} \mathrm{C}$ with the ramp of $10{ }^{\circ} \mathrm{C} / \mathrm{min}$ to $90{ }^{\circ} \mathrm{C}$. After every temperature increase (either $5{ }^{\circ} \mathrm{C}$ or $10{ }^{\circ} \mathrm{C}$ ), the samples were kept for 10 minutes at constant temperature and then images were taken.

Modulated differential scanning calorimetry (M-DSC) was used to estimate the extent of interpenetration of the two polymers.[59] For a completely phase separated system, the derivative of the heat capacity $\left(\mathrm{dC}_{\mathrm{p}} / \mathrm{dT}\right)$ presents two peaks, the maxima are the glass transition temperatures of the polymers and the $\mathrm{dC}_{\mathrm{p}} / \mathrm{dT}$ between the two peaks is close to the baseline. When intermixing occurs, the $\mathrm{dC}_{\mathrm{p}} / \mathrm{dT}$ in the region between the two peaks is higher than the baseline and the peaks are smaller and maybe closer to each other. The samples were dried at ambient temperature, which is lower than the $\mathrm{Tg}_{\mathrm{g}}$ of the softer phase in the polymer composite latex, to prevent the film formation that can change particle morphology [60]. Samples were characterized using the method reported by Jiang et al[61]. The measurements were carried out in a Q2000 equipment (TA instruments). The results of the first heating cycle were considered to represent the morphology of polymer particles as changes in the morphology are expected upon heating.

Minimum film forming temperatures (MFFT) were measured in an MFFT bar. A wet layer of latex with $90 \mu \mathrm{m}$ of thickness was formed on the metal bar that had a temperature gradient. The lowest temperature at which a transparent film had a uniform knife cut after one hour of film formation was considered as MFFT. 


\section{Results and discussion}

Figures 1, 4 and 5 present the evolution of the instantaneous conversions and particle morphology during the seeded emulsion copolymerization for the cases were the $\mathrm{Tg}$ of the seed was modified $\left(86^{\circ} \mathrm{C}, 63{ }^{\circ} \mathrm{C}\right.$ and $46^{\circ} \mathrm{C}$ for Cases 1,2 and 3 , respectively). The Tg of the second stage copolymer was $45-49^{\circ} \mathrm{C}$.

It can be seen in Figure 1 that the average instantaneous conversion was about $94 \%$ based on total polymer plus monomer in the reactor in the first 90 minutes, namely that the polymer particles contained about $6 \%$ of monomer. The amount of monomer in the polymer particles determined the effective Tgs as the monomer plasticizes the polymers. The effective $\mathrm{Tg}$ of the seed can be estimated as follows: [62]

$$
T_{g}=\frac{T_{g p}+\left(\kappa T_{g M}-T_{g P}\right) \phi_{M}}{1+(\kappa-1) \phi_{M}}
$$

where $\mathrm{TgP}_{\mathrm{gP}}$ and $\mathrm{T}_{\mathrm{gM}}$ are glass transition temperatures of polymer 1 and monomer $2, \phi_{M}$ is the monomer fraction in the polymer and $\kappa$ is a constant varying from 1 to $3[62]$ that was taken to be

2. $\mathrm{T}_{\mathrm{gM}}$ can be estimated as $\frac{2}{3} T_{\text {meltM }}$, where $\mathrm{T}_{\text {meltm }}$ is the melting point of the monomer [63]. The $\mathrm{TgM}_{\mathrm{gM}}$ of the S/BA monomer mixture was calculated using the $\mathrm{T}_{\text {melt }}$ of monomers[64] and the Flory-Fox equation. Considering that, $\phi_{M}=0.06, \mathrm{~T}_{\mathrm{gP}}=359 \mathrm{~K}$ and $\mathrm{T}_{\mathrm{gM}}=154 \mathrm{~K}$, the estimated effective $\mathrm{Tg}$ of the seed was $62.8{ }^{\circ} \mathrm{C}$, namely below the reaction temperature. Figure 1 presents the evolution of the particle morphology as measured by cryo-TEM (Figure 1a) and by TEM of samples stained with $\mathrm{RuO}_{4}$ (Figure 1b). Figure 1a gives a good image of the surface topography mainly at the beginning of the process and particle morphology is better seen in Figure 1b (dark areas in the images corresponds to the styrene rich second stage polymer). Figure 1 shows that at the early stages of the reaction (30 min sample), many small lobes were formed on the surface of 
the particles (this is more clearly seen in Figure 1a). The size of the lobes increased and their number decreased with time during the semi-continuous operation. The lobes grew by the combined effect of polymerization and coagulation. No significant changes of the particle morphologies were observed during post-polymerization. It is worth mentioning that the postpolymerization process was performed at a temperature lower than the $\mathrm{Tg}$ of the hardest phase in the composite latex particles. The images in Figure 1 suggest that the lobes accounted for most of the second stage polymer, namely, that even though the inverted core-shell (i.e. with the PS rich polymer in the core) was the equilibrium morphology, there was almost no penetration of the second stage polymer in the seed. This can be due to strong concentration profiles of radicals and/or monomer. However, the simulations presented in Supporting Information (Figure S1) show that the monomer was homogeneously distributed within the polymer particles. Therefore, the observed effect should be due to a rapidly decreasing radical concentration profile. It is worth mentioning that the redox initiator used in the semibatch process produced non-charged hydrophobic radicals in the aqueous phase. Therefore, the radical concentration profile was not due to anchoring of the entering radical to the surface of the particle, but to the slow diffusion of the growing polymer chain through the particles.

The results presented in Figure 1 suggest that the surface of the particles was covered by lobes of the PS rich polymer. However, the MFFT of this latex was $80^{\circ} \mathrm{C}$, which is much higher than the $\mathrm{Tg}$ of the lobes $\left(45^{\circ} \mathrm{C}\right)$ and closer to the $\mathrm{Tg}$ of the polymer forming the seed. This is inconsistent with a particle morphology with $50 \%$ of the polymer forming soft lobes on the particle surface. Particle coalescence was further checked by ESEM measurements at different temperatures. Figure 2 shows that the multi-lobed composite particles started to coalesce after 10 minutes at a temperature between $60{ }^{\circ} \mathrm{C}$ and $70{ }^{\circ} \mathrm{C}$. 


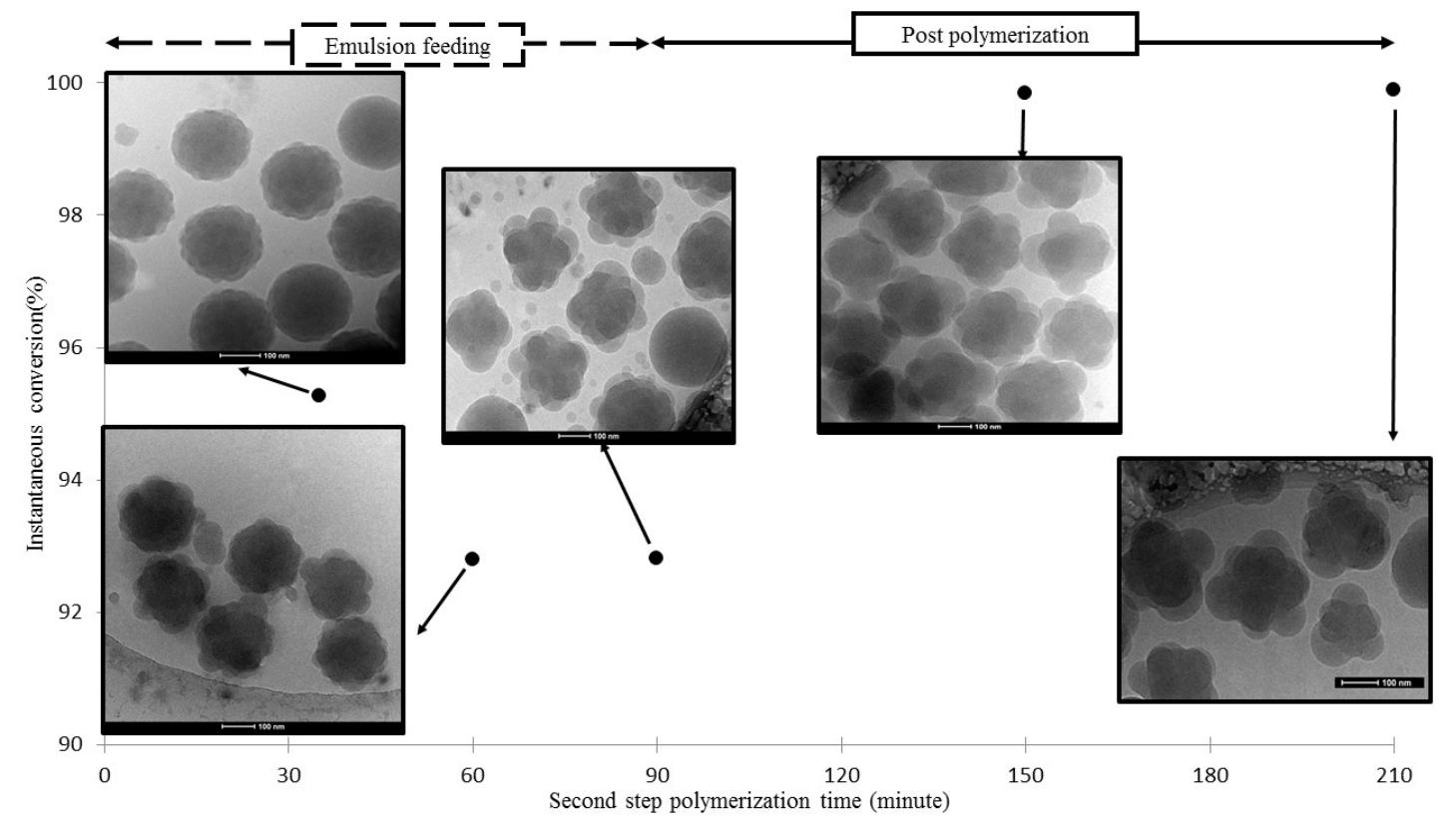

(a)

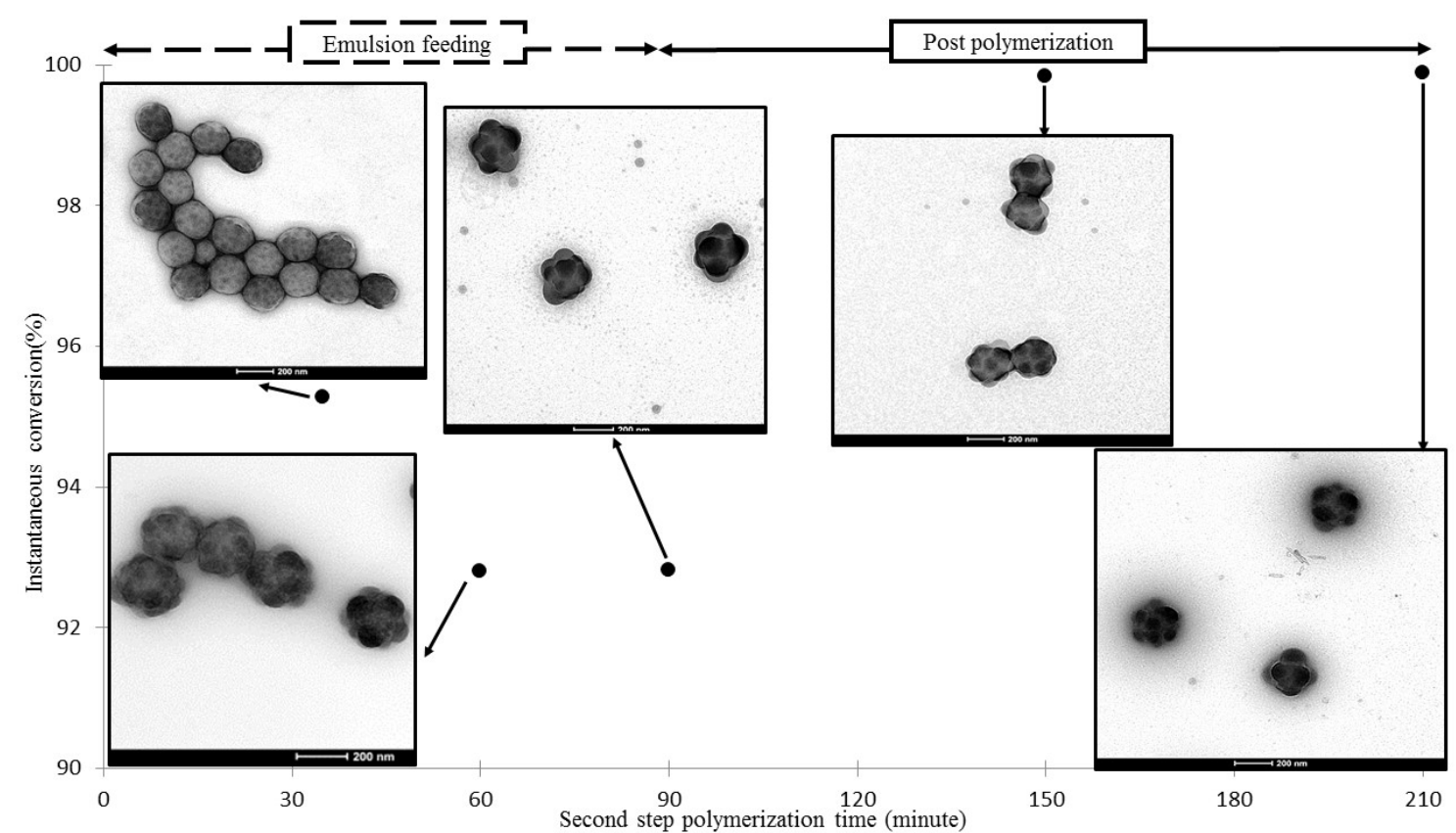

(b)

Figure 1. Evolution of the instantaneous conversion and particle morphology during the seeded emulsion polymerization (Case $1, \operatorname{Tg}_{\text {seed }}=86^{\circ} \mathrm{C}$ ) a) Cryo-TEM images, scale bar is $100 \mathrm{~nm}$ (image magnification: 50000); b) TEM image of $\mathrm{RuO}_{4}$ stained samples, scale bar is $200 \mathrm{~nm}$ (image magnification: 25000). 
(a) $30^{\circ} \mathrm{C}$

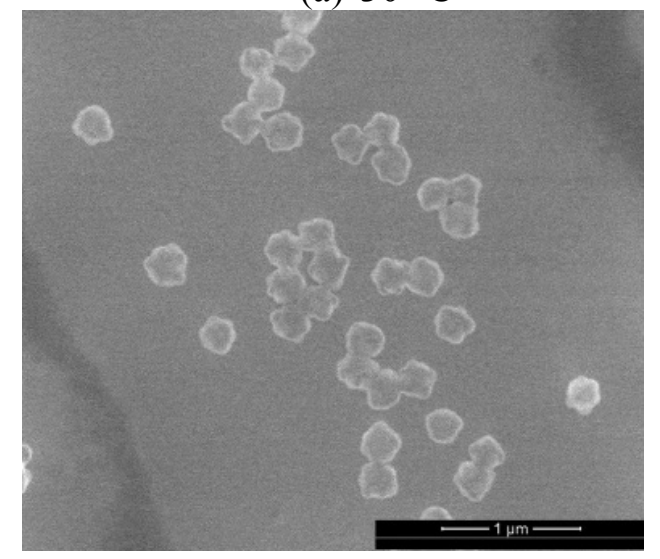

(c) $45^{\circ} \mathrm{C}$

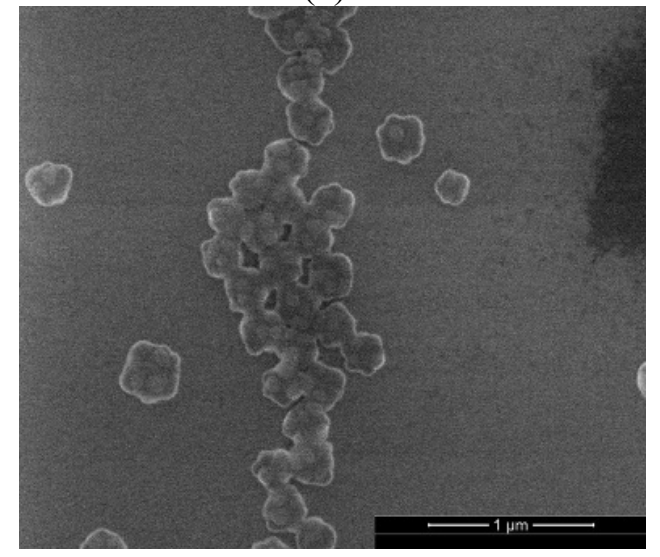

(e) $60{ }^{\circ} \mathrm{C}$

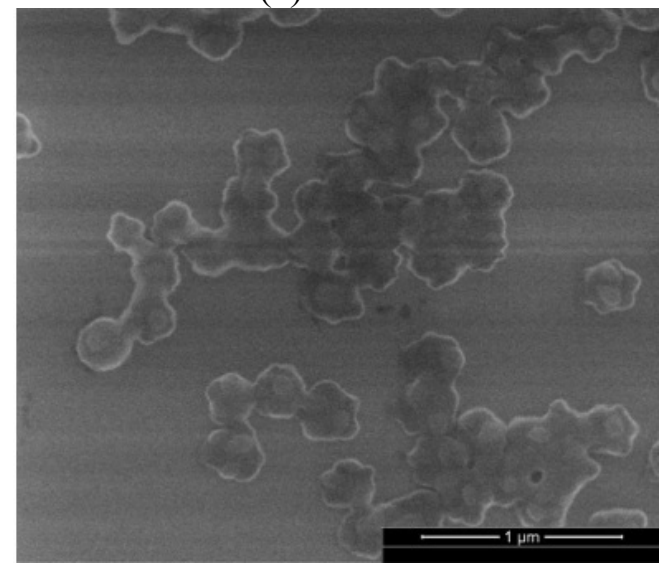

(b) $40^{\circ} \mathrm{C}$

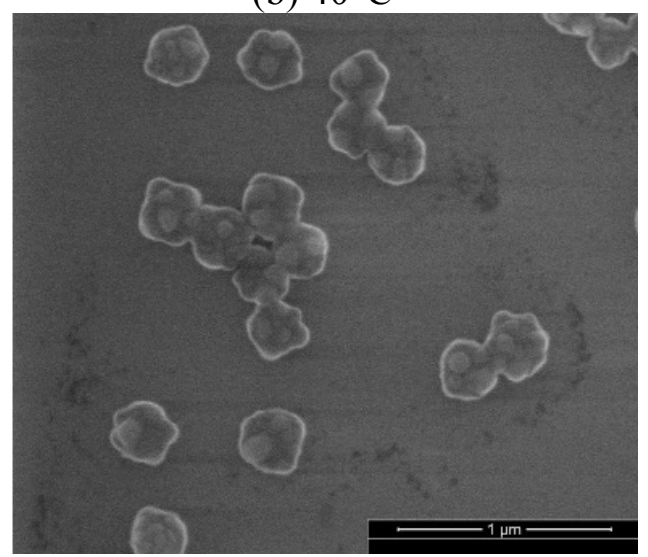

(d) $50{ }^{\circ} \mathrm{C}$

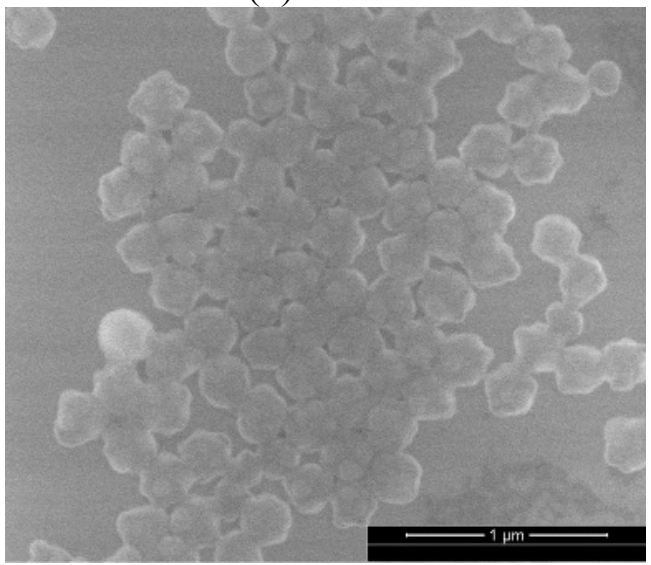

(f) $70^{\circ} \mathrm{C}$

Figure 2-Coalescence of Case 1 polymer particles in the ESEM at different temperatures:

(a) $30^{\circ} \mathrm{C}$; (b) $40^{\circ} \mathrm{C}$; (c) $45^{\circ} \mathrm{C}$; (d) $50^{\circ} \mathrm{C}$; (e) $60^{\circ} \mathrm{C}$; (f) $70^{\circ} \mathrm{C}$. Heating ramp between temperatures:

$10^{\circ} \mathrm{C} / \mathrm{min}$. Time at each constant temperature: $10 \mathrm{~min}$ 
The high temperature needed to form a film can be due to lower effective fraction of the soft polymer on the surface due to a high level of interpenetration between two polymers. However, no proof for this interpenetration was found in the modulated DSC experiments for Case 1. Figure 3 shows two clear peaks and that the value of $\mathrm{dCp} / \mathrm{dT}$ in the region between peaks was close to the baseline, which indicates that there was not intermixing between the polymers. This is further supported by the fact that there was no difference between the first and second cycles. It is worth pointing out that the differences in the baseline in the glassy and the rubbery regions are due to the difference in temperature sensitivity of the $C_{p}$ of the polymer in glass and melt states[65]. A possible reason for the high MFFT is that the PS-rich clusters were embedded in the hard polymer forming the seed, so that the external surface of the lobes was formed by the MMA-rich polymer, which hindered film formation at low temperatures.

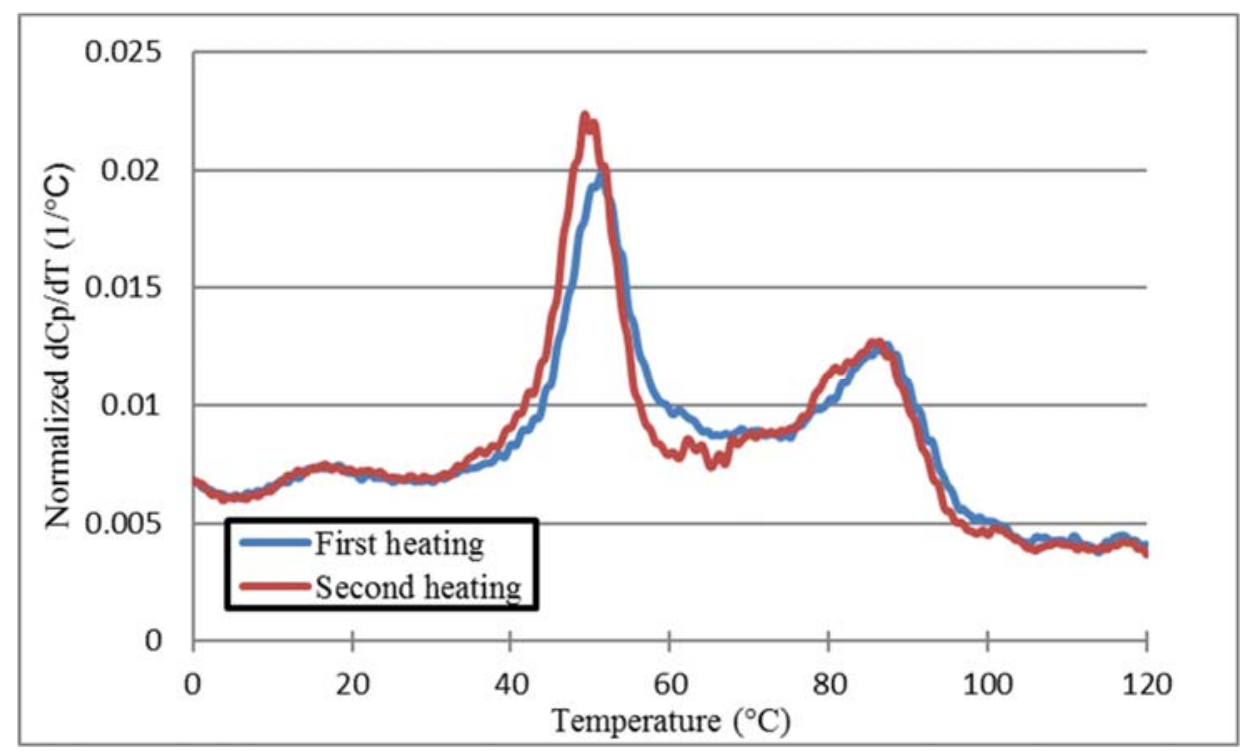

Figure $3-\mathrm{dC}_{\mathrm{p}} / \mathrm{dT}$ from M-DSC for Case 1.

Figure 4 presents the evolution of the instantaneous conversion and the particle morphology for Case 2 that used a seed with a $\mathrm{Tg}=63^{\circ} \mathrm{C}$. The process was carried out under very starved 
conditions (the average instantaneous conversion was 98.5\%). Taking into account the free monomer in the system, the effective $\mathrm{Tg}$ of the seed calculated with equation 1 was $57.6{ }^{\circ} \mathrm{C}$, namely below the reaction temperature.

Figure 4 shows that at the beginning of the process clusters of the second stage polymer were formed near the surface of the particles, but not as close to the surface as in Case 1 (Figure 1). During the reaction, the size of clusters increased and their number decreased, likely due to the combined effect of polymerization within the clusters and coagulation between them. At the end of the process, multilobbed polymer particles were obtained although the clusters forming the lobes were better embedded in the particle than for Case 1 . The difference was attributed to the lower $\mathrm{Tg}$ of the seed that allowed more migration of the clusters toward the inverted core-shell equilibrium morphology.

The minimum film forming temperature for this latex was $60^{\circ} \mathrm{C}$, which was very close to $\mathrm{Tg}$ of the seed $\left(63^{\circ} \mathrm{C}\right)$. ESEM images of Case 2 showed that particle coagulation started at $51^{\circ} \mathrm{C}$ (supporting information, Figure S3). These results indicate that in this case also the surface of the clusters of the second stage polymer were covered by the MMA-rich harder polymer. 


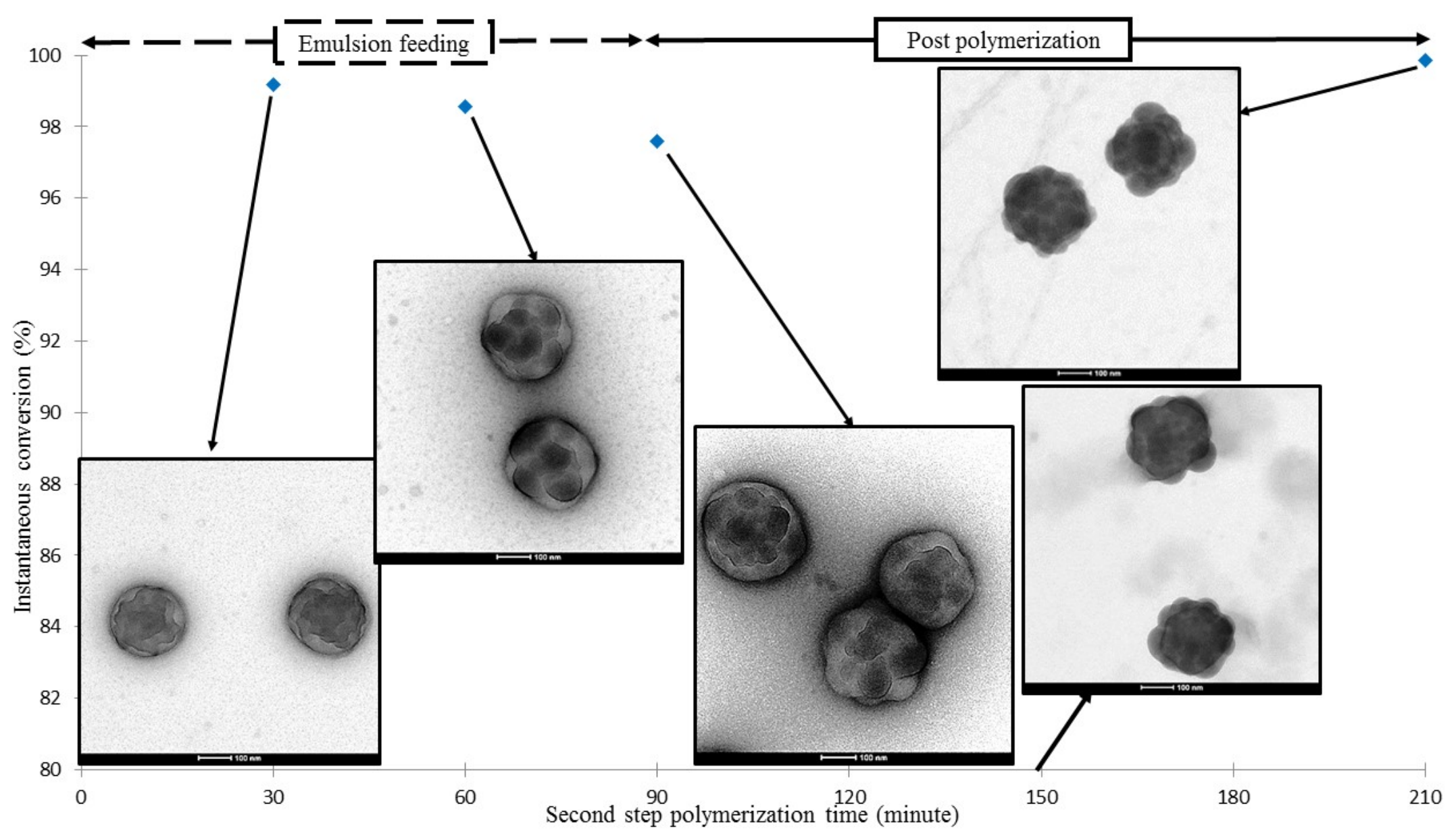

Figure 4. Evolution of the instantaneous conversion and particle morphology (TEM images of the $\mathrm{RuO}_{4}$ stained samples) during the seeded emulsion polymerization (Case $2, \operatorname{Tg}_{\text {seed }}=63^{\circ} \mathrm{C}$ ). Scale bar is $100 \mathrm{~nm}$ (image magnification of 50000 ). 
Figure 5 presents the evolution of the instantaneous conversion and particle morphology for Case 3 where a seed with a $\mathrm{Tg}=46^{\circ} \mathrm{C}$ was used. Taking into account the free monomer, the effective $\mathrm{Tg}$ of the seed was estimated to be $26.5^{\circ} \mathrm{C}$. As in Cases 1 and 2, initially many small clusters were formed that later evolved to larger and fewer ones. The main difference with respect to the previous cases is that the clusters penetrated more within the particle and relatively spherical particles were obtained at the end of the process. The reason was the low effective Tg of the seed that allowed migration of the clusters and perhaps a faster diffusion of the radicals that might result in a flatter radical concentration in the particles. In this case, the MMFT does not provide any information about the morphology because both polymers have the same $\mathrm{Tg}$.

The evolutions of the particle morphology presented above were analyzed using a recently developed mathematical model.[53] In this model, the particle morphology is characterized by means of cluster size distributions (in a similar way as a polymer is characterized by the molar mass distribution). The model accounts for the radical concentration profile and the profile was discretized in two regions, one close to the surface and the other representing the rest of the particle as illustrated in Figure 6. The model distinguishes between clusters at equilibrium positions (for the cases in this work, the equilibrium position was the center of the particle) and non-equilibrium positions (see Figure 6). In addition, the discretization of the radical concentration profile divides the clusters at non-equilibrium profile into two distributions. Therefore, the particle morphology is characterized by three distributions as illustrated in Figure 6. 


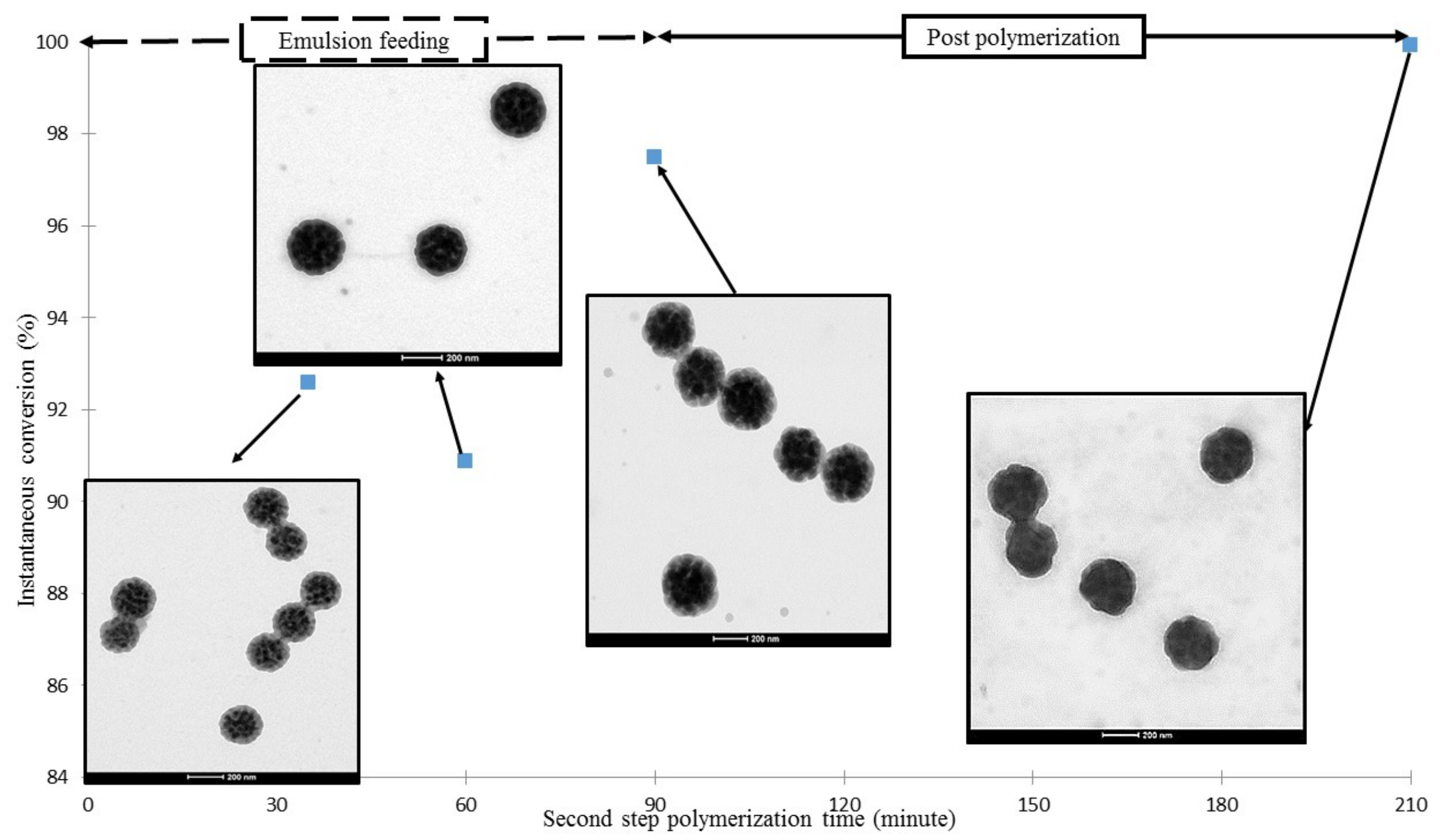

Figure 5. Evolution of the instantaneous conversion and particle morphology (TEM images of the RuO4 stained samples) during the seeded emulsion polymerization (Case $3, \operatorname{Tg}_{\text {seed }}=46^{\circ} \mathrm{C}$ ). Scale bar is $200 \mathrm{~nm}$ (image magnification of 25000 ). 

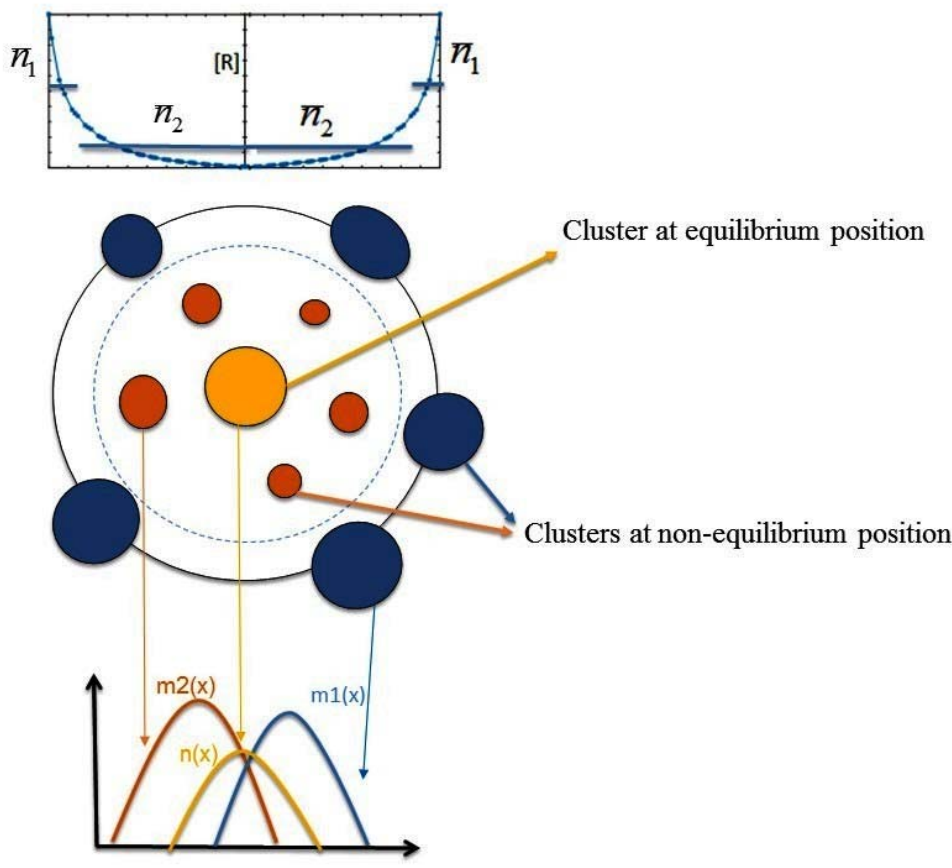

Figure 6. Illustration of the equilibrium and non-equilibrium positions considered in the mathematical model.

The population balances of the three types of the clusters, the balance for the radical concentration profile and the values of the parameters are given in the Supporting Information. The adjustable parameters of the model are the rate coefficient of coagulation $\left(k_{a 0}\right)$, movement of the clusters to the non-equilibrium interior region and to the equilibrium position $\left(k_{m o v 1}, k_{m o v 2}\right)$, the mass transfer coefficient of the polymer from matrix to the clusters $\left(k_{d 0}^{p o l 2}\right)$ and the cluster nucleation rate coefficient $\left(k_{n}\right)$. In the model, a defined size $\left(x_{c}\right.$, monomer units) was considered as the size of the nucleated clusters and it was shown in the previous work that in a certain range, this size does not affect the particle morphology[53]. In addition, to calculate the radical diffusion coefficient a constant kinetic chain length for the growing radical was assumed and a dependency parameter to the chain length $(\beta)$ was estimated 
(see SI for details). The model accounts for the effect of the operation variables (such as effective glass transition of the medium, instantaneous conversion, temperature, etc.) on the adjustable parameters of the model and hence on the particle morphology. It is worth mentioning that due to the limited available experimental images and the fact that the TEM provides $2 \mathrm{D}$ images with no clear indication of the location of the clusters, transferring of the morphologies of the TEM images to a distribution was not possible. Therefore comparison between simulated and experimental morphologies was made visually.

Figures 7-9 present a comparison of the experimental evolution of the particle morphology and the mass cluster distribution predicted by the model with the parameters given in the Table S1 in the Supporting Information for Cases 1-3. It can be seen that the model captured well the evolution of the particle morphology. Figure 7 shows that for Case 1 where a high $\mathrm{Tg}$ seed $\left(86^{\circ} \mathrm{C}\right)$ was used, the model predicted that most of the second stage polymer was in the outer part of the non-equilibrium positions. Figure 8 shows that for Case $2\left(\mathrm{Tg}\right.$ seed $\left.=63^{\circ} \mathrm{C}\right)$, most of the second stage polymer was at non-equilibrium positions, and the main part of it was in the inner region of the non-equilibrium positions. This is in good agreement with the TEM images that show that the clusters are more embedded in the particle than for Case 1. For Case 3 (Figure 9) where the softest seed $\left(\operatorname{Tg}\right.$ seed $\left.=46^{\circ} \mathrm{C}\right)$ was used, the amount of second stage polymer in the outer shell of the non-equilibrium position was very small and the styrene rich polymer was distributed between the clusters in the inner region of the non-equilibrium positions and the core (equilibrium position). This is in a nice agreement with the TEM images of the particles that show that at the end of the process no cluster was at the surface of the particles. 


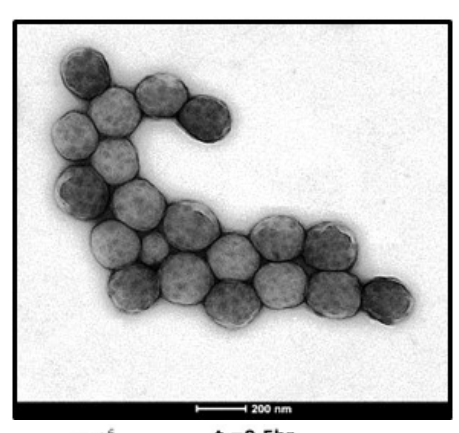

$\mathrm{t}=0.5 \mathrm{hr}$
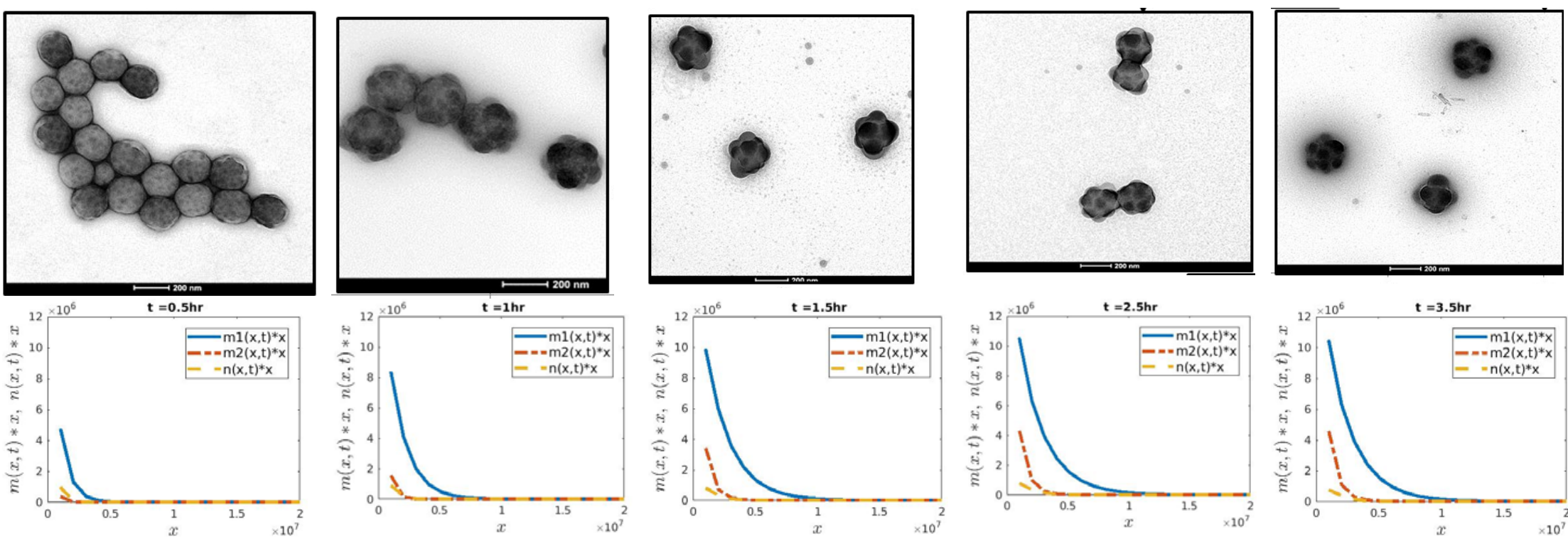

Figure 7. Comparison between the evolution of the experimental particle morphology and the predicted mass cluster distributions for Case 1. ( $\mathrm{m} 1$ (blue): clusters in the outer shell of the non-equilibrium positions; $\mathrm{m} 2$ (orange): clusters in the inner region of the nonequilibrium positions; $n$ (yellow): clusters at equilibrium positions). Scale bar is $200 \mathrm{~nm}$ (image magnification of 25000) in the TEM images. 


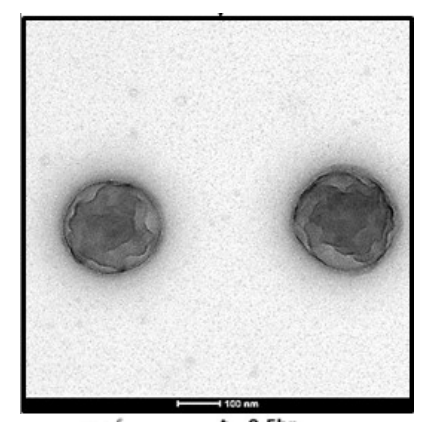

$t=0.5 \mathrm{hr}$
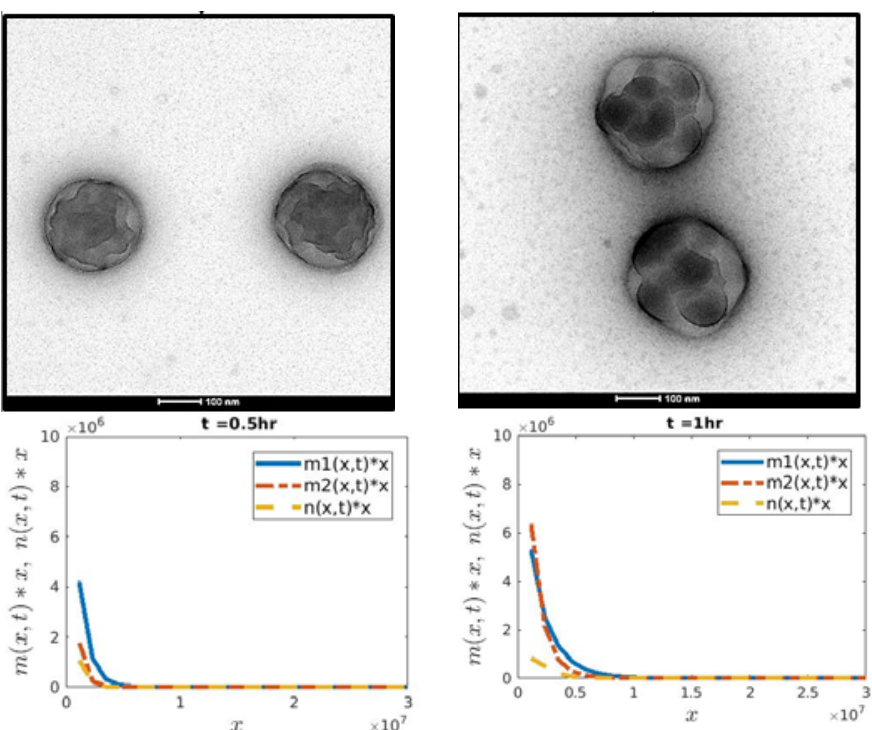

$t=1 \mathrm{hr}$
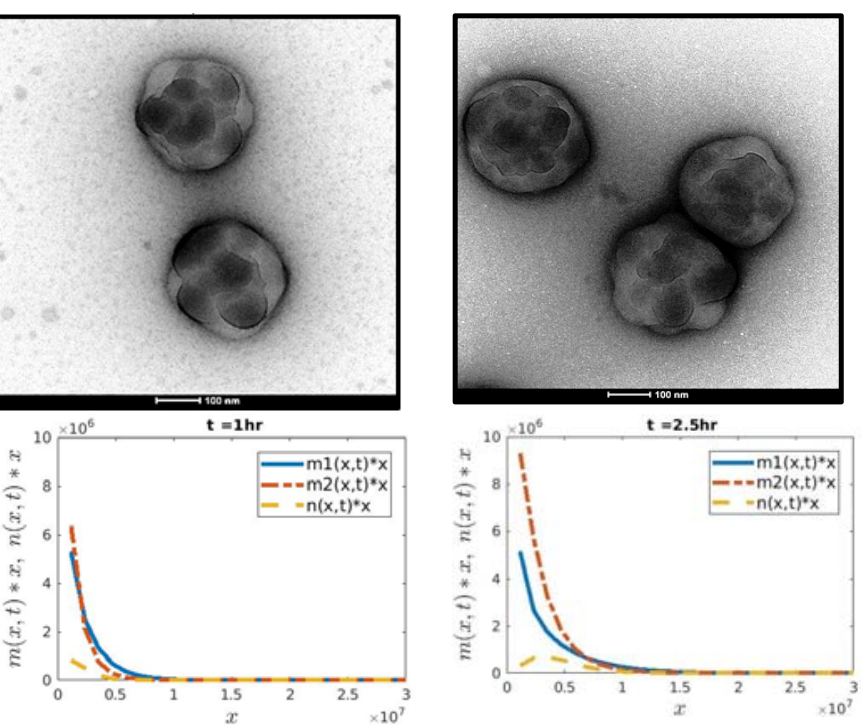

$t=2.5 \mathrm{hr}$
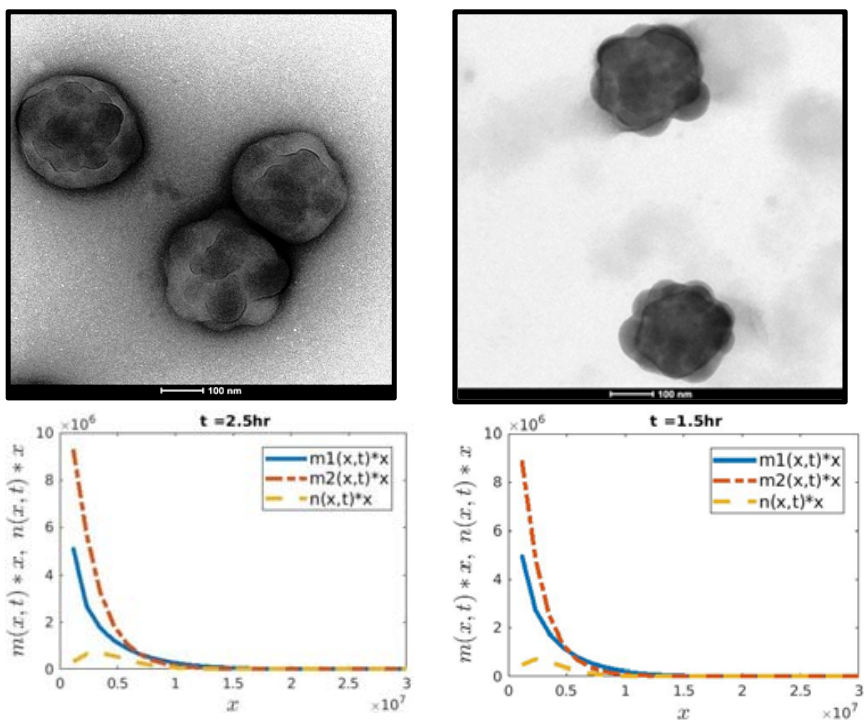

$\mathrm{t}=1.5 \mathrm{hr}$
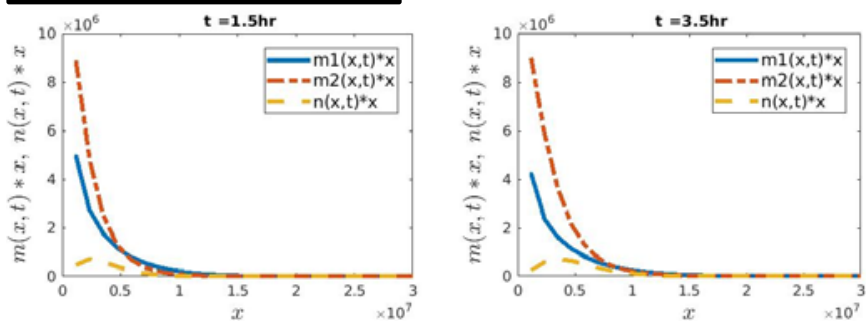

Figure 8. Comparison between the evolution of the experimental particle morphology and the predicted mass cluster distributions for Case 2. (m1 (blue): clusters in the outer shell of the non-equilibrium positions; $\mathrm{m} 2$ (orange): clusters in the inner region of the nonequilibrium positions; $n$ (yellow): clusters at equilibrium positions). Scale bar is $100 \mathrm{~nm}$ (image magnification of 50000) in TEM images. 

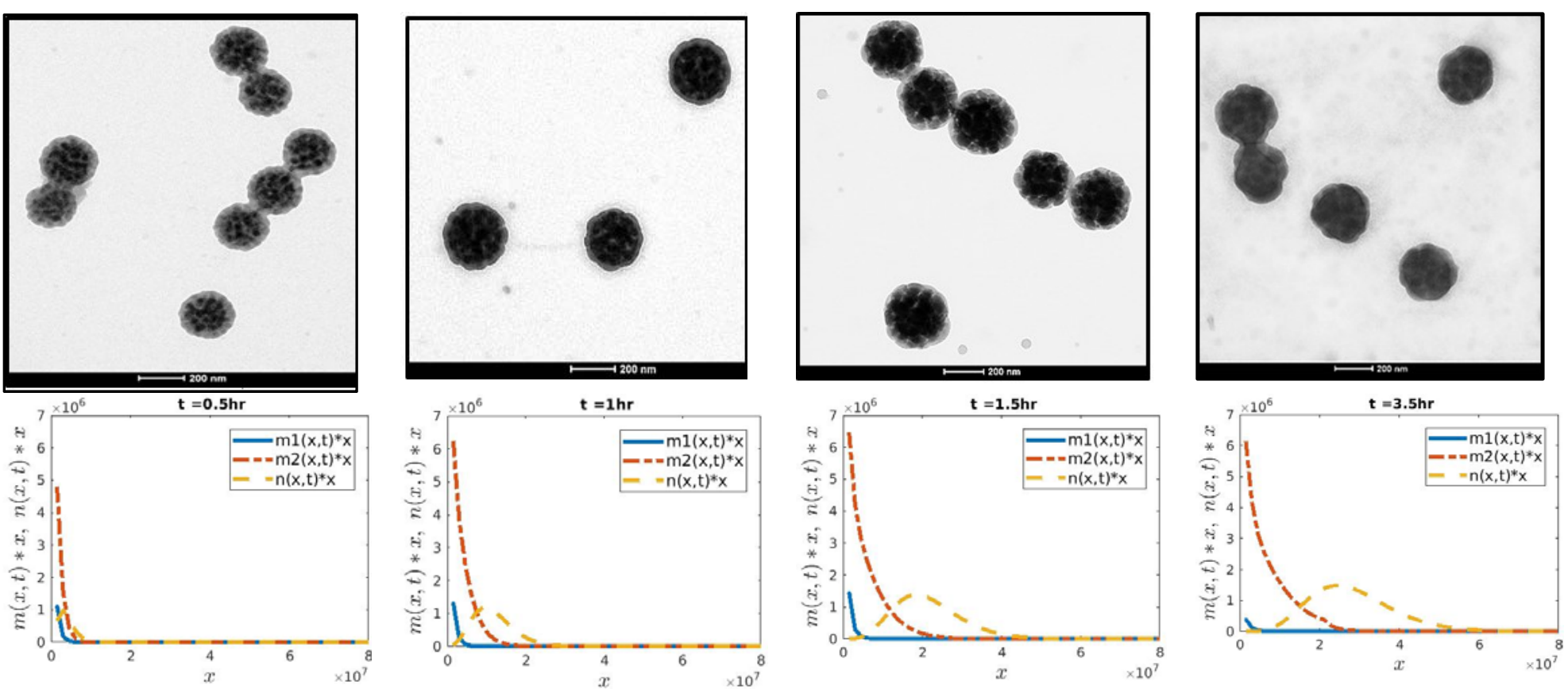

Figure 9. Comparison between the evolution of the experimental particle morphology and the predicted mass cluster distributions for Case 3. ( $\mathrm{m} 1$ (blue): clusters in the outer shell of the non-equilibrium positions; $\mathrm{m} 2$ (orange): clusters in the inner region of the nonequilibrium positions; $n$ (yellow): clusters at equilibrium positions). Scale bar is $200 \mathrm{~nm}$ (image magnification of 25000) in TEM images. 
Figure 10 gives a visual comparison of the TEM images of the final samples and the TEM-like images generated from the distributions in Figures 7-9 (see reference 54 for details on how the TEM-like images are obtained). It can be seen that the model captured very well the experimental observations.

Case 1
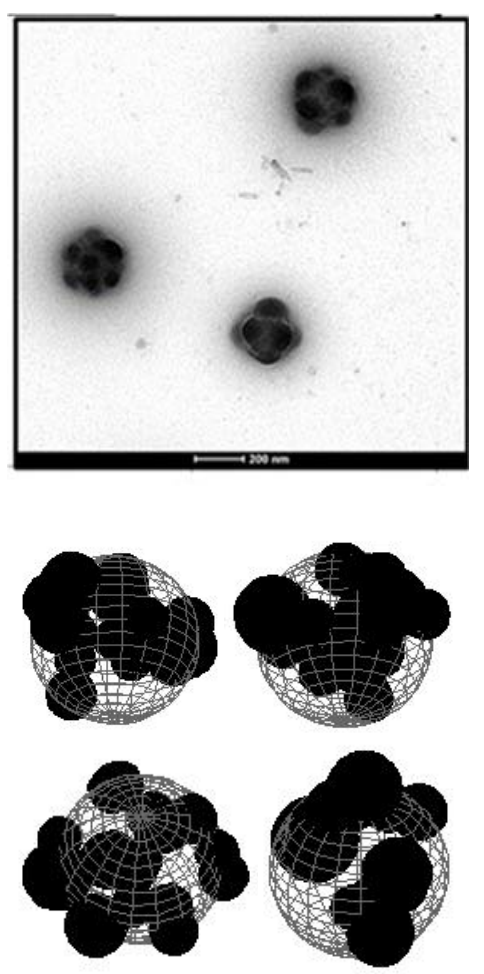

Case 2
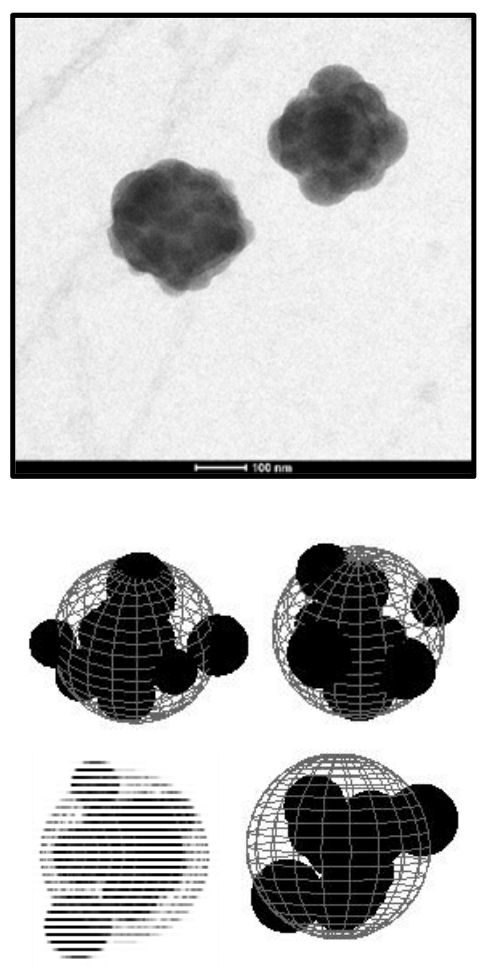

Case 3
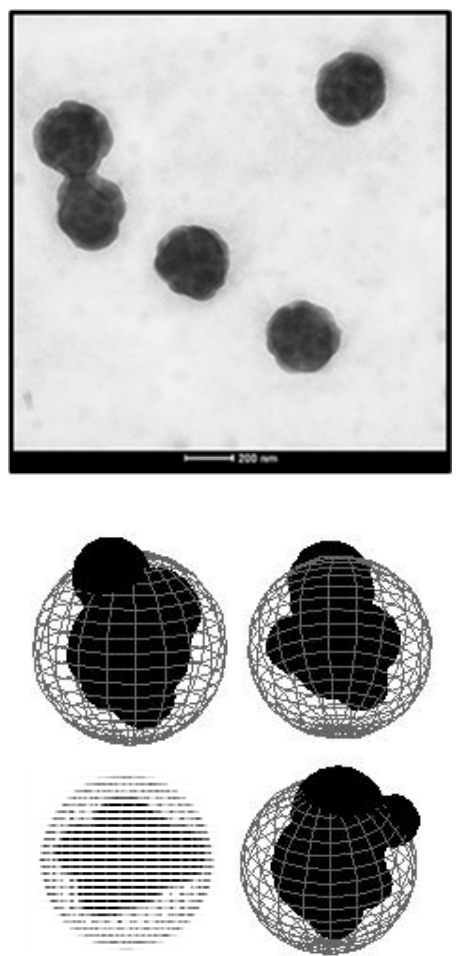

Figure 10. Comparison between the TEM images of the final samples and the TEM-like particles generated from the cluster distributions.

\section{Conclusions:}

Polymer-polymer composite nanoparticles have opened a wide range of new application for waterborne dispersions and their performance strongly depends on particle morphology. This has triggered the research in the field that has provided qualitative guidance for the effect of the 
process variables on the particle morphology. However, for the design and the implementation of optimal polymerization strategies a mathematical model is needed.

This work aims at evaluating the capability of a recently developed model for the development of the morphology of waterborne composite particles to describe the evolution of the particle morphology during seeded semi-batch emulsion polymerizations. This is the most widely used process for the production of waterborne polymer-polymer hybrids.

Poly (MMA-co-BA) seeds with different $\operatorname{Tgs}\left(86^{\circ} \mathrm{C}, 63^{\circ} \mathrm{C}\right.$ and $\left.46^{\circ} \mathrm{C}\right)$ were prepared by semicontinuous emulsion polymerization using various MMA/BA ratios. The second stage polymer was a copolymer of styrene and butyl acrylate with a $\mathrm{Tg}$ of $45-49^{\circ} \mathrm{C}$. This copolymer was more hydrophobic than the seed, therefore, the equilibrium morphology was inverted core-shell. The evolution of the morphology was determined by Cryo TEM and TEM of $\mathrm{RuO}_{4}$ stained samples. It was found that in the initial stages of the process, many of small lobes were formed at the surface of the seed. The size of the lobes increased and their number decreased by the combined effect of polymerization and coagulation. The softer the seed, the more the lobes penetrate in the particles.

The performance of the model was checked against the experimental data finding that the model captured well the effect of the process variables on the evolution of the particle morphology. This opens the way to both process optimization and online control of the particle morphology.

\section{Acknowledgements:}

The financial support of the RECOBA project (funding from European Framework Horizon 2020, No. 636820) is gratefully acknowledged. The authors acknowledge Prof. John Tsavalas from the University of New Hampshire for fruitful discussions on M-DSC experiments. The authors acknowledge Dr. G. Patricia Leal for the ESEM characterization and Dr. Mariano 
Barrado and Dr. Ana Amesti of SGIker of UPV/EHU for Cryo-TEM and TEM characterizations.

S. Hamzehlou acknowledges the University of the Basque Country (UPV/EHU) for the

“Contratación para la especialización de personal investigador doctor” postdoctoral grant.

\section{References:}

[1] M.F. Haase, D.O. Grigoriev, H. Möhwald, D.G. Shchukin, Development of Nanoparticle Stabilized Polymer Nanocontainers with High Content of the Encapsulated Active Agent and Their Application in Water-Borne Anticorrosive Coatings, Adv. Mater. 24 (2012) $2429-2435$.

[2] O. ur Rahman, M. Kashif, S. Ahmad, Nanoferrite dispersed waterborne epoxy-acrylate: Anticorrosive nanocomposite coatings, Prog. Org. Coatings. 80 (2015) 77-86.

[3] J. Yang, H. Liang, L. Zeng, S. Liu, T. Guo, Facile Fabrication of Superhydrophobic Nanocomposite Coatings Based on Water-Based Emulsion Latex, Adv. Mater. Interfaces. 5 (2018) 1800207.

[4] H. Palza, Antimicrobial Polymers with Metal Nanoparticles, Int. J. Mol. Sci. 16 (2015) 2099-116.

[5] I. Martín-Fabiani, A. Fortini, J. Lesage De La Haye, M.L. Koh, S.E. Taylor, E. BourgeatLami, M. Lansalot, F. D’Agosto, R.P. Sear, J.L. Keddie, PH-Switchable Stratification of Colloidal Coatings: Surfaces “on Demand,” ACS Appl. Mater. Interfaces. 8 (2016) 34755-34761.

[6] J. Chen, W. Zhong, Y. Tang, Z. Wu, Y. Li, P. Yi, J. Jiang, Amphiphilic BODIPY-Based Photoswitchable Fluorescent Polymeric Nanoparticles for Rewritable Patterning and DualColor Cell Imaging, Macromolecules. 48 (2015) 3500-3508.

[7] M. Zhu, X. Huang, K. Yang, X. Zhai, J. Zhang, J. He, P. Jiang, Energy storage in ferroelectric polymer nanocomposites filled with core-shell structured polymer@BaTiO3nanoparticles: Understanding the role of polymer shells in the interfacial regions, ACS Appl. Mater. Interfaces. 6 (2014) 19644-19654.

[8] H. Wang, L. Zhao, G. Song, G. Tang, X. Shi, Organic-inorganic hybrid shell microencapsulated phase change materials prepared from $\mathrm{SiO} 2 / \mathrm{TiC}$-stabilized pickering emulsion polymerization, Sol. Energy Mater. Sol. Cells. 175 (2018) 102-110.

[9] X.Y. Wu, Strategies for optimizing polymer-lipid hybrid nanoparticle-mediated drug 
delivery, Expert Opin. Drug Deliv. 13 (2016) 609-612.

[10] Z. Zhou, C. Kennell, J.-Y. Lee, Y.-K. Leung, P. Tarapore, Calcium phosphate-polymer hybrid nanoparticles for enhanced triple negative breast cancer treatment via co-delivery of paclitaxel and miR-221/222 inhibitors, Nanomedicine Nanotechnology, Biol. Med. 13 (2017) 403-410.

[11] V. Dave, R.B. Yadav, K. Kushwaha, S. Yadav, S. Sharma, U. Agrawal, Lipid-polymer hybrid nanoparticles: Development \& statistical optimization of norfloxacin for topical drug delivery system, Bioact. Mater. 2 (2017) 269-280.

[12] H.J. Bae, S. Bae, C. Park, S. Han, J. Kim, L.N. Kim, K. Kim, S.H. Song, W. Park, S. Kwon, Biomimetic microfingerprints for anti-counterfeiting strategies, Adv. Mater. 27 (2015) 2083-2089.

[13] K. Kim, M. Suh, J. Choi, D. Lee, Y. Kim, S.H. Cheong, D. Kim, D.Y. Jeon, Conjugated Polyelectrolyte Hybridized ZnO Nanoparticles as a Cathode Interfacial Layer for Efficient Polymer Light-Emitting Diodes, Adv. Funct. Mater. 25 (2015) 7450-7456.

[14] D.C. Sundberg, Y.G. Durant, Latex Particle Morphology, Fundamental Aspects: A Review, Polym. React. Eng. 11 (2003) 379-432.

[15] Y. Reyes, E. Akhmatskaya, J.R. Leiza, J.M. Asua, Particle Morphology, in: A.M. van Herk (Ed.), Chem. Technol. Emuls. Polym., Second ed., John Wiley \& Sons, Ltd, Singapore, 2013.

[16] T.I. Min, A. Klein, M.S. El-Aasser, J.W. Vanderhoff, Morphology and grafting in polybutylacrylate-polystyrene core-shell emulsion polymerization, J. Polym. Sci. Polym. Chem. Ed. 21 (1983) 2845-2861.

[17] J.-E. Joensson, H. Hassander, B. Toernell, Polymerization Conditions and the Development of a Core-Shell Morphology in PMMA/PS Latex Particles. 1. Influence of Initiator Properties and Mode of Monomer Addition, Macromolecules. 27 (1994) 19321937.

[18] D.I. Lee, T. Ishikawa, The formation of "inverted" core-shell latexes, J. Polym. Sci. Polym. Chem. Ed. 21 (1983) 147-154.

[19] S. Kirsch, A. Doerk, E. Bartsch, H. Sillescu, K. Landfester, H.W. Spiess, W. Maechtle, Synthesis and characterization of highly cross-linked, monodisperse core-shell and inverted core-shell colloidal particles. Polystyrene/ poly(tert-butyl acrylate) core-shell and 
inverse core-shell particles, Macromolecules. 32 (1999) 4508-4518.

[20] H.R. Sheu, M.S. El-Aasser, J.W. Vanderhoff, Phase separation in polystyrene latex interpenetrating polymer networks, J. Polym. Sci. Part A Polym. Chem. 28 (1990) 629651.

[21] D.C. Sundberg, A.P. Casassa, J. Pantazopoulos, M.R. Muscato, B. Kronberg, J. Berg, Morphology Development of Polymeric Microparticles in Aqueous Dispersions. I. Thermodynamic Considerations, J. Appl. Polym. Sci. 41 (1990) 1425-1442.

[22] V. Herrera, Z. Palmillas, R. Pirri, Y. Reyes, J.R. Leiza, J.M. Asua, Morphology of ThreePhase PS/PBA Composite Latex Particles Containing in Situ Produced Block Copolymers, Macromolecules. 43 (2010) 1356-1363.

[23] M. Okubo, Y. Katsuta, T. Matsumoto, Rupture of anomalous composite particles prepared by seeded emulsion polymerization in aging period, J. Polym. Sci. Polym. Lett. Ed. 18 (1980) 481-486.

[24] M. Okubo, T. Nakagawa, Formation of multihollow structures in crosslinked composite polymer particles, Colloid Polym. Sci. 272 (1994) 530-535.

[25] W. Deng, R. Li, M. Zhang, L. Gong, C. Kan, Influences of MAA on the porous morphology of P(St-MAA) latex particles produced by batch soap-free emulsion polymerization followed by stepwise alkali/acid post-treatment, J. Colloid Interface Sci. 349 (2010) 122-126.

[26] B. Li, Y. Xu, M. Wang, X. Ge, Morphological Control of Multihollow Polymer Latex Particles through a Controlled Phase Separation in the Seeded Emulsion Polymerization, Langmuir. 29 (2013) 14787-14794.

[27] W. Zhai, B. Wang, Y. Wang, Y.F. He, P. Song, R.M. Wang, An efficient strategy for preparation of polymeric Janus particles with controllable morphologies and emulsifiabilities, Colloids Surfaces A Physicochem. Eng. Asp. 503 (2016) 94-100.

[28] F. Jasinski, V. Teo, R.P. Kuchel, M. Mballa Mballa, S.C. Thickett, R.H.G. Brinkhuis, W. Weaver, P.B. Zetterlund, Synthesis and Characterisation of Gradient Polymeric Nanoparticles, Polym. Chem. 8 (2017) 495-499.

[29] F. Jasinski, V.L. Teo, R.P. Kuchel, M. Mballa Mballa, S.C. Thickett, R.H.G. Brinkhuis, W. Weaver, P.B. Zetterlund, Core-Shell and Gradient Morphology Polymer Particles Analyzed by X- Ray Photoelectron Spectroscopy: Effect of Monomer Feed Order, J. 
Polym. Sci. Part A Polym. Chem. 55 (2017) 2513-2526.

[30] A. Hosseini, A.E. Bouaswaig, S. Engell, Novel approaches to improve the particle size distribution prediction of a classical emulsion polymerization model, Chem. Eng. Sci. 88 (2013) 108-120.

[31] P. Pladis, A.H. Alexopoulos, C. Kiparissides, Mathematical Modeling and Simulation of Vinylidene Fluoride Emulsion Polymerization, Ind. Eng. Chem. Res. 53 (2014) 73527364.

[32] I. Calvo, K. Hester, J.R. Leiza, J.M. Asua, Mathematical Modeling of Carboxylated SB Latexes, Macromol. React. Eng. 8 (2014) 329-346.

[33] L. Hlalele, D.R. D’hooge, C.J. Dürr, A. Kaiser, S. Brandau, C. Barner-Kowollik, RAFTMediated ab Initio Emulsion Copolymerization of 1,3-Butadiene with Acrylonitrile, Macromolecules. 47 (2014) 2820-2829.

[34] S. Hamzehlou, N. Ballard, P. Carretero, M. Paulis, J.M. Asua, Y. Reyes, J.R. Leiza, Mechanistic investigation of the simultaneous addition and free-radical polymerization in batch miniemulsion droplets: Monte Carlo simulation versus experimental data in polyurethane/acrylic systems, Polymer. 55 (2014) 4801-4811.

[35] C.A. Capeletto, C. Costa, C. Sayer, P.H.H. Araújo, Mathematical Modeling of Molecular Weight Distribution in Miniemulsion Polymerization with Oil-Soluble Initiator, AIChE J. 63 (2017) 2128-2140.

[36] M.F. Mills, R.G. Gilbert, D.H. Napper, Effect of polymerization kinetics on particle morphology in heterogeneous systems, Macromolecules. 23 (1990) 4247-4257.

[37] J. Stubbs, O. Karlsson, J.E. Jönsson, E. Sundberg, Y. Durant, D. Sundberg, Nonequilibrium particle morphology development in seeded emulsion polymerization. 1 : Penetration of monomer and radicals as a function of monomer feed rate during second stage polymerization, Colloids Surfaces A Physicochem. Eng. Asp. 153 (1999) 255-270.

[38] M.R. Grancio, D.J. Williams, The Morphology of the Monomer-Polymer Particle in Styrene Emulsion Polymerization, J. Polym. Sci. Part A-1 Polym. Chem. 8 (1970) 26172629 .

[39] C.-S. Chern, G.W. Poehlein, Polymerization in Nonuniform Latex Particles: Distribution of Free Radicals, J. Polym. Sci. Part A Polym. Chem. 25 (1987) 617-635.

[40] D.H. Napper, Particle Morphology in Emulsion Polymerization, J. Polym. Sci. Part A-1 
Polym. Chem. 9 (1971) 2089-2091.

[41] J.C. de La Cal, R. Urzay, A. Zamora, J. Forcada, J.M. Asua, Simulation of the Latex Particle Morphology, J. Polym. Sci. Part A Polym. Chem. 28 (1990) 1011-1031.

[42] J.M. Stubbs, D.C. Sundberg, Fundamental Studies on Morphology Control For Latex Systems with Application to Waterborne Coatings: The Effect of Polymer Radical Mobility In Latex Particles During Polymerization, J. Coatings Technol. 75 (2003) 59-67.

[43] L.E. Karlsson, O.J. Karlsson, D.C. Sundberg, Nonequilibrium Particle Morphology Development in Seeded Emulsion Polymerization. II. Influence of Seed Polymer Tg Lina, J. Appl. Polym. Sci. 90 (2003) 905-915.

[44] J.M. Stubbs, D.C. Sundberg, Nonequilibrium Particle Morphology Development in Seeded Emulsion Polymerization. III. Effect of Initiator End Groups, J. Appl. Polym. Sci. $91(2004) 1538-1551$.

[45] J.M. Stubbs, D.C. Sundberg, Nonequilibrium Morphology Development in Seeded Emulsion Polymerization. V. The Effect of Crosslinking Agent, J. Appl. Polym. Sci. 102 (2006) 2043-2054.

[46] J. Stubbs, J. Tsavalas, R. Carrier, D. Sundberg, The Structural Evolution of Composite Latex Particles During Starve-Fed Emulsion Polymerization: Modeling and Experiments for Kinetically Frozen Morphologies, Macromol. React. Eng. 4 (2010) 424-431.

[47] J.M. Stubbs, D.C. Sundberg, Nonequilibrium Morphology Development in Seeded Emulsion Polymerization. IV. Influence of Chain Transfer Agent, J. Appl. Polym. Sci. 102 (2006) 945-957.

[48] C.S. Chou, A. Kowalski, J.M. Rokowski, E.J. Schaller, Nonspherical Acrylic Latices, J. Coatings Technol. 59 (1987) 93-102.

[49] A. Kowalski, J.J. Wilczynski, R.M. Blankenship, C.-S. Chou, Multilobals, US5030666A, 1988.

[50] D. Blenner, J. Stubbs, D. Sundberg, Multi-lobed composite polymer nanoparticles prepared by conventional emulsion polymerization, Polymer. 114 (2017) 54-63.

[51] J.M. Stubbs, D.C. Sundberg, The dynamics of morphology development in multiphase latex particles, Prog. Org. Coatings. 61 (2008) 156-165.

[52] J.M.M. Faust, S. Hamzehlou, J.R. Leiza, J.M. Asua, A. Mhamdi, A. Mitsos, Dynamic Optimization of a Two-Stage Emulsion Polymerization to Obtain Desired Particle 
Morphologies, Accepted in Chem. Eng. J. (2018).

[53] S. Hamzehlou, J.R. Leiza, J.M. Asua, A new approach for mathematical modeling of the dynamic development of particle morphology, Chem. Eng. J. 304 (2016) 655-666.

[54] S. Hamzehlou, M. Aguirre, J.R. Leiza, J.M. Asua, Dynamics of the Particle Morphology during the Synthesis of Waterborne Polymer-Inorganic Hybrids, Macromolecules. 50 (2017) 7190-7201.

[55] M. Paulis, J.M. Asua, Knowledge-Based Production of Waterborne Hybrid Polymer Materials, Macromol. React. Eng. 10 (2016) 8-21.

[56] T.G. Fox, Influence of diluent and of copolymer composition on the glass temperature of a polymer system, Bull. Am. Phys. Soc. 1 (1956) 123-132.

[57] T.C. Baroni, B.J. Griffin, J.R. Browne, F.J. Lincoln, Correlation between Charge Contrast Imaging and the Distribution of Some Trace Level Impurities in Gibbsite, Microsc. Microanal. 6 (2000) 49-58.

[58] K. González-Matheus, G.P. Leal, J.M. Asua, Film formation from Pickering stabilized waterborne polymer dispersions, Polymer. 69 (2015) 73-82.

[59] J.M. Stubbs, D.C. Sundberg, Measuring the Extent of Phase Separation During Polymerization of Composite Latex Particles Using Modulated Temperature DSC, J. Polym. Sci. Part B Polym. Phys. 43 (2005) 2790-2806.

[60] J.L. Keddie, Film formation of latex, Mater. Sci. Eng. 21 (1997) 101-170.

[61] B. Jiang, J. Tsavalas, D. Sundberg, Measuring the Glass Transition of Latex-Based Polymers in the Hydroplasticized State via Differential Scanning Calorimetry, Langmuir. 26 (2010) 9408-9415.

[62] F. Bueche, Rate and Pressure Effects in Polymers and Other GlassForming Substances, J. Chem. Phys. 36 (1962) 2940.

[63] M. Vonka, M. Soos, G. Storti, Viscosity and Drop Size Evolution During Suspension Polymerization, AIChE J. 62 (2016) 4229-4239.

[64] J. Brandrup, E.H. Immergut, E.A. Grulke, eds., Polymer handbook, Forth ed., WileyInterscience, 2004.

[65] A.K. Tripathi, J.G. Tsavalas, D.C. Sundberg, Quantitative measurements of the extent of phase separation during and after polymerization in polymer composites using DSC, Thermochim. Acta. 568 (2013) 20-30. 


\title{
Supporting Information
}

\section{Experimental validation of a mathematical model for the evolution of the particle morphology of waterborne polymer-polymer hybrids: paving the way to the design and implementation of optimal polymerization strategies}

\author{
Noushin Rajabalinia, Shaghayegh Hamzehlou, Jose R. Leiza, José M. Asua*
}

POLYMAT, Kimika Aplikatua saila, Kimika Zientzien Fakultatea, University of the Basque Country UPV/EHU, Joxe Mari Korta Zentroa, Tolosa Hiribidea 72, 20018, Donostia-San Sebastian, Spain

Monomer and radical concentration profiles:

The monomer concentration profile in the polymer particle was calculated via solving the following partial differential equation by orthogonal collocation[1]:

$$
\frac{\partial[M](t, r)}{\partial t}=\nabla^{2} D_{M}[M](t, r)-k_{p}[R](t, r)[M](t, r)
$$

where $[M](t, r)$ and $[R](t, r)$ are the monomer and radical concentrations at time $t$ and radius of $r$, respectively. $D_{M}$ is the monomer diffusion coefficient and $k_{p}$ is the propagation rate coefficient. 
The diffusion constant of the monomer $D_{M}$ was calculated using a modified Vrentas-Duda freevolume model of small molecule diffusion in binary polymer solutions[2]:

$$
\begin{gathered}
\log D_{M}=\log D^{\circ}-\frac{E}{2.303 R T}-\frac{1}{2.303}\left[\frac{\left(1-w_{2}\right) \widehat{V}_{1}^{*}+£ w_{2} \widehat{V}_{2}^{*}}{\frac{\widehat{V}_{f}}{\gamma}}\right] \\
\frac{\hat{V}_{f}}{\gamma}=\left(1-w_{2}\right)\left(\frac{K_{11}}{\gamma}\right)\left(K_{21}+T-T g_{1}\right)+w_{2}\left(\frac{K_{12}}{\gamma}\right)\left[K_{22}+a\left(T-T g_{2}\right)\right.
\end{gathered}
$$

where $D^{\circ}$ and $E$ are the pre-exponential factor and activation energy of the monomer diffusion coefficient, respectively. $a$ is the ratio between the coefficients of thermal expansion of the polymer below and above $\mathrm{T}_{\mathrm{g}}$ of polymer. $\frac{K_{11}}{\gamma}, \frac{K_{12}}{\gamma}, K_{21}, K_{22}$ are free volume parameters. $T g_{1}$ and $T g_{2}$ are monomer and polymer glass transition temperatures, respectively. $T$ is the reaction temperature. $\widehat{V}_{1}^{*}$ and $\widehat{V}_{2}^{*}$ are specific volumes of monomer and polymer, respectively. $w_{2}$ is the weight fraction of polymer. $€$ is the size parameter[2] and $\frac{\widehat{V}_{f}}{\gamma}$ is the solution free volume. The values of the parameters used are given in Table S1.

Figure S1 shows a representative monomer concentration profile in the particle with a $[M]\left(0, r_{p}\right)=0.377 \mathrm{~mol} / \mathrm{L}$ (which corresponds to $\left.\phi_{\text {Pol }}=0.96\right)$ and $\operatorname{Tg}_{\text {seed }}=90^{\circ} \mathrm{C}$ at $T_{\text {reaction }}=$ $80^{\circ} \mathrm{C}$. 


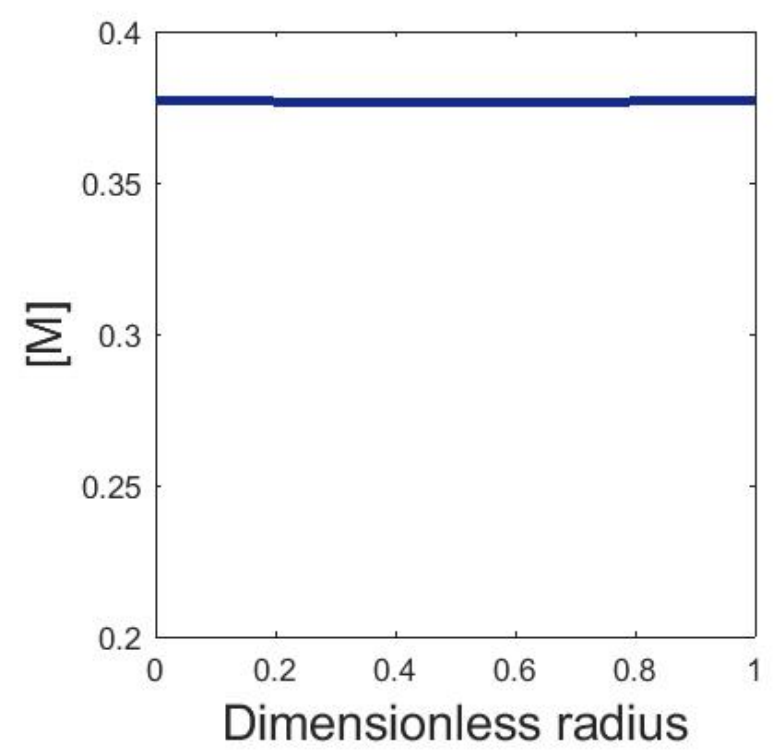

Figure S1. Monomer concentration profile in the particle (mol/L) with $D_{M}=3.17 \times 10^{-14} \mathrm{~m}^{2} / \mathrm{s}$. $\left([M]\left(0, r_{p}\right)=0.377 \mathrm{~mol} / \mathrm{L}\right.$ (which corresponds to $\left.\phi_{P o l}=0.96\right)$ and $\mathrm{Tg}_{\text {seed }}=90^{\circ} \mathrm{C}$ at $\mathrm{T}_{\text {reaction }}=$ $\left.80^{\circ} \mathrm{C}\right)$.

The radical concentration profile in the polymer particle was calculated via solving the following partial differential equation by orthogonal collocation on finite elements. [1]

$$
\frac{\partial[R](t, r)}{\partial t}=D_{R} \nabla^{2}[R](t, r)-k_{t}[R]^{2}(t, r)
$$

where $D_{R}$ is the radical diffusion coefficient and $k_{t}$ is the termination rate coefficient. It is worth mentioning that the redox initiator used in the semibatch process produced non-charged hydrophobic radicals in the aqueous phase. Therefore, anchoring of the entering radical to the surface of the particle was not considered. The diffusion coefficient for radicals was reported to show a power-law variation with chain length[3]. In this work a constant kinetic chain length for the growing radical was assumed in the simulations (half of the degree of the polymerization of polymer $2,\left(\bar{x}_{m}\right)$ considering that termination reaction occurs by combination) and dependency parameter $(\beta)$ was considered as adjusting parameter: 


$$
D_{R}=\frac{D_{M}}{\left(\bar{x}_{m} / 2\right)^{\beta}}
$$

The value of the parameters are presented in Table S1. Figure S2 shows a representative radical concentration profile in the particle with $[M](t, r)=0.377 \mathrm{~mol} / \mathrm{L}$ (corresponds to the $\phi_{P o l}=$ 0.96) and $\mathrm{Tg}_{\text {seed }}=90^{\circ} \mathrm{C}$ at $\mathrm{T}_{\text {reaction }}=80^{\circ} \mathrm{C}$.

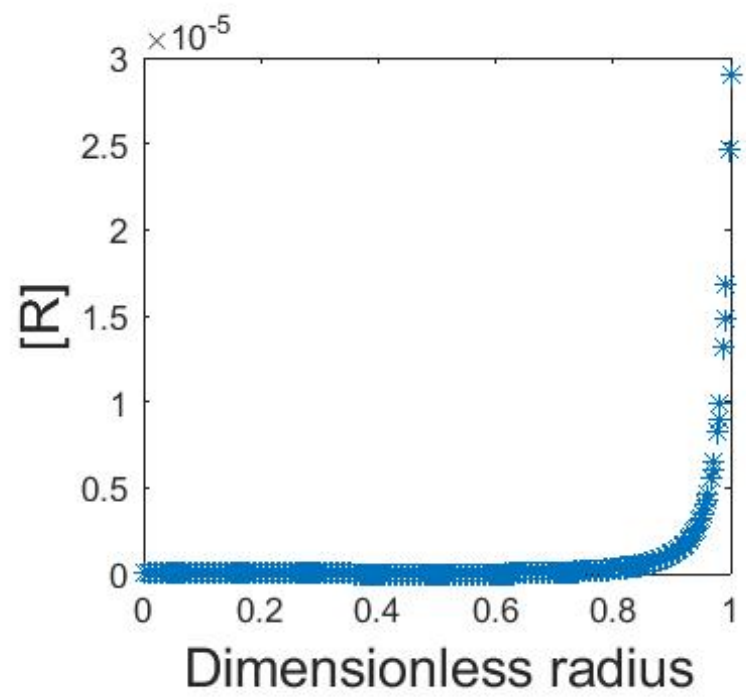

Figure S2. Radical concentration profile (mol/L) in the particle with $D_{R}=2.04 \times 10^{-16} \mathrm{~m}^{2} / \mathrm{s}$. $\left([M](t, r)=0.377 \mathrm{~mol} / \mathrm{L}\right.$ (corresponds to the $\left.\phi_{P o l}=0.96\right)$ and $\mathrm{Tg}_{\text {seed }}=90^{\circ} \mathrm{C}$ at $\mathrm{T}_{\text {reaction }}=80^{\circ} \mathrm{C}$ ). 
(a) $20{ }^{\circ} \mathrm{C}$

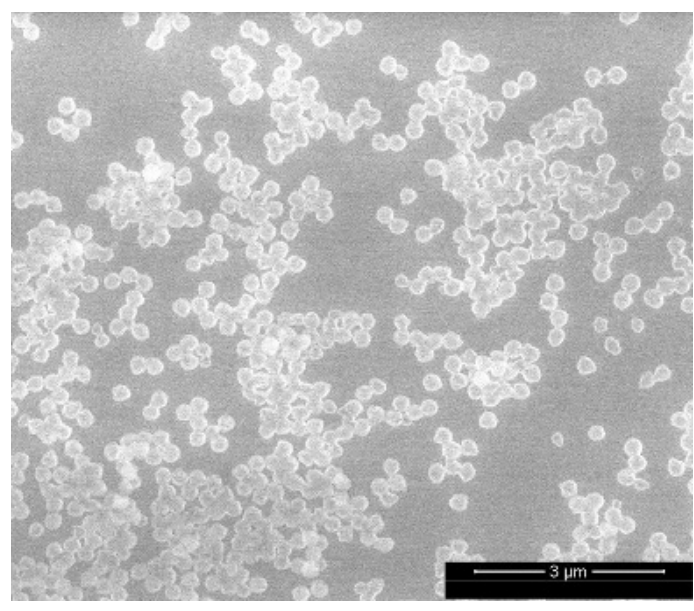

(c) $40{ }^{\circ} \mathrm{C}$

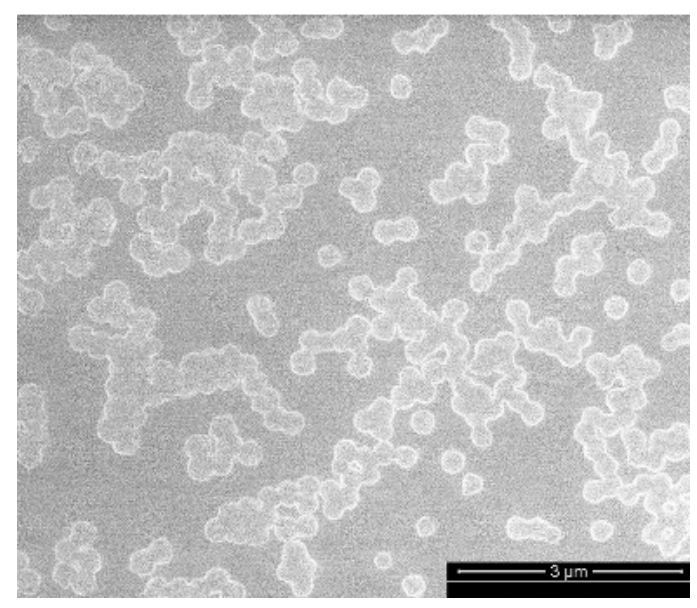

(b) $30^{\circ} \mathrm{C}$

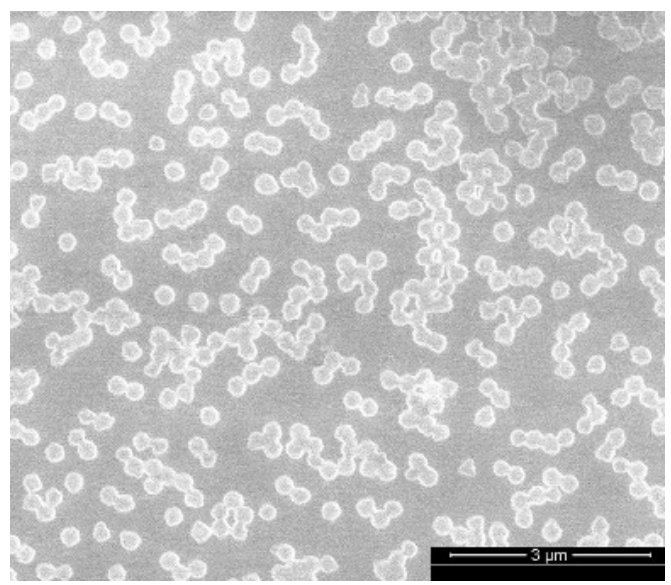

(d) $51{ }^{\circ} \mathrm{C}$

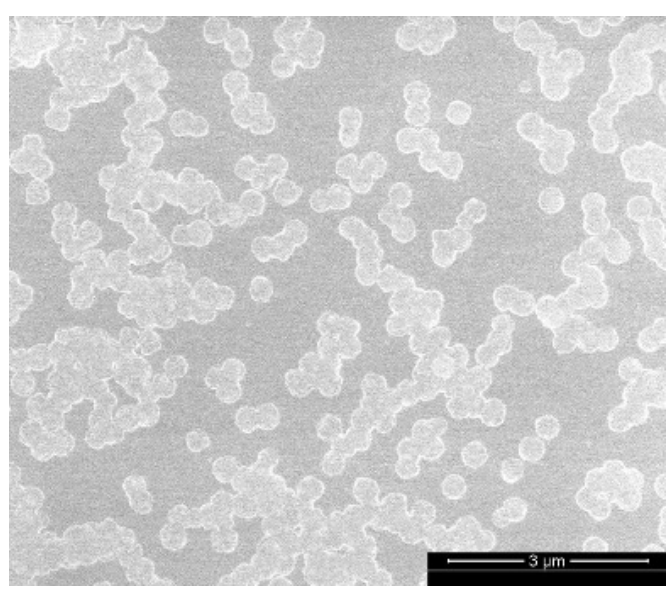

Figure S3-Coalescence of latex Case 2 polymer particles in the ESEM at different temperatures: (a) $20^{\circ} \mathrm{C}$; (b) $30^{\circ} \mathrm{C}$; (c) $40^{\circ} \mathrm{C}$; (d) $51^{\circ} \mathrm{C}$. Heating ramp between temperatures was $10^{\circ} \mathrm{C} / \mathrm{min}$. Waiting time at each constant temperature was $10 \mathrm{~min}$. 
Population balances of clusters at non-equilibrium and equilibrium positions:

$$
\begin{gathered}
\frac{d m 1(x)}{d t}=\left(1-\delta_{x_{c}}\right) r_{p}^{m 1}(x-1) m 1(x-1)-r_{p}^{m 1}(x) m 1(x) \\
+\left(1-\delta_{x c}\right) r_{d}^{m 1}\left(x-\bar{x}_{m}\right) m 1\left(x-\bar{x}_{m}\right)-r_{d}^{m 1}(x) m 1(x) \\
+\left(1-\delta_{x \leq 2 x_{c}}\right) \alpha_{m}(x) \frac{k_{a}}{V_{p}}\left(1-\frac{1}{m 1_{a v}}\right) \int_{x_{c}}^{x-x_{c}} m 1(z) m 1(x-z) d z \\
-2 m 1(x) \frac{k_{a}}{V_{p}}\left(1-\frac{1}{m 1_{a v}}\right) \int_{x_{c}}^{x_{m a x}-x} \alpha_{m}(x+z) m 1(z) d z \\
-k_{m o v 1} m 1(x)+\delta_{x_{c}} r_{n u c} \\
+2 m 2(x) \frac{k_{a}}{V_{p}}\left(1-\frac{1}{m 2_{a v}}\right) \int_{x_{c}}^{x_{m a x}-x} \alpha_{m}(x+z) m 2(z) d z \\
\frac{d m 2(x)}{d t}=\left(1-\delta_{x_{c}}\right) r_{p}^{m 2}(x-1) m 2(x-1)-r_{p}^{m 2}(x) m 2(x) \\
+\left(1-\delta_{x c}\right) r_{d}^{m 2}\left(x-\bar{x}_{m}\right) m 2\left(x-\bar{x}_{m}\right)-r_{d}^{m 2}(x) m 2(x) \\
\left.+\delta_{x \leq 2}\right) \alpha_{m}(x) \frac{k_{a}}{V_{p}}\left(1-\frac{1}{m 2_{a v}}\right) \int_{x_{c}}^{x-x_{c}} m 2(z) m 2(x-z) d z \\
-m 2(x) \frac{k_{m o v 2}}{V_{p}} \int_{x_{c}}^{x_{m a x}-x} \alpha_{m}(x+z) n(z)+\delta_{x_{c}} r_{n u c}
\end{gathered}
$$




$$
\begin{aligned}
& \frac{d n(x)}{d t}=\left(1-\delta_{x_{c}}\right) r_{p}^{n}(x-1) n(x-1)-r_{p}^{n}(x) n(x) \\
& +\left(1-\delta_{x_{c}}\right) r_{d}^{n}\left(x-\bar{x}_{m}\right) n\left(x-\bar{x}_{m}\right)-r_{d}^{n}(x) n(x) \\
& +\left(1-\delta_{x \leq 2 x_{c}}\right) \alpha_{n}(x) \frac{k_{m o v 2}}{V_{p}} \int_{x_{c}}^{x-x_{c}} m 2(z) n(x-z) d z \\
& -n(x) \frac{k_{\operatorname{mov} 2}}{V_{p}} \int_{x_{c}}^{x_{\max }-x} \alpha_{n}(x+z) m 2(z) d z
\end{aligned}
$$

\begin{tabular}{|c|c|c|}
\hline Parameter & value & Reference \\
\hline$k_{p, B A}(\mathrm{~L} / \mathrm{mol} . \mathrm{s})$ & $2.21 \times 10^{7} \exp (-17.9 / \mathrm{RT})$ & [4] \\
\hline$k_{p, S t}(\mathrm{~L} / \mathrm{mol} . \mathrm{s})$ & $4.27 \times 10^{7} \exp (-32.5 / \mathrm{RT})$ & [5] \\
\hline rSt & 0.95 & [6] \\
\hline rBA & 0.18 & {$[6]$} \\
\hline$k_{a 0}(L / s)^{+}$ & $1 \times 10^{-22}$ & This work \\
\hline$k_{\text {mov } 1}(1 / s)^{+}$ & $1 \times 10^{-3}$ & This work \\
\hline$k_{\text {mov } 2}(L / s)^{+}$ & $8 \times 10^{-5}$ & This work \\
\hline$k_{d 0}^{p o l 2}\left(\mathrm{~mol} / \mathrm{dm}^{2} . \mathrm{s}\right)^{+}$ & $5 \times 10^{-10}$ & This work \\
\hline$k_{n}(\mathrm{~mol} / \mathrm{s})^{+}$ & $5 \times 10^{-2}$ & This work \\
\hline$x_{c}$ (monomeric units) $^{+}$ & $4 \times 10^{4}$ & [7] \\
\hline $\bar{x}_{m}(\text { monomeric units })^{+}$ & $5 \times 10^{3}$ & [7] \\
\hline \multicolumn{3}{|c|}{ Parameters for monomer and radical diffusion coefficient calculations ++} \\
\hline $\mathrm{D}^{\circ}\left(\mathrm{cm}^{2} / \mathrm{s}\right)$ & $1.61 \times 10^{-3}$ & {$[2]$} \\
\hline $\mathrm{E}(\mathrm{cal} / \mathrm{mol})$ & 778 & [2] \\
\hline$£$ & 0.6 & {$[2]$} \\
\hline$\widehat{V}_{1}^{*}\left(\mathrm{~cm}^{3} / \mathrm{g}\right)$ & 0.87 & {$[2]$} \\
\hline$\widehat{V}_{2}^{*}\left(\mathrm{~cm}^{3} / \mathrm{g}\right)$ & 0.757 & {$[2]$} \\
\hline$\frac{K_{11}}{\gamma}\left(\mathrm{cm}^{3} / \mathrm{g} . \mathrm{K}\right)$ & $0.815 \times 10^{-3}$ & {$[2]$} \\
\hline$K_{21}(\mathrm{~K})$ & 143 & {$[2]$} \\
\hline$\frac{K_{12}}{\gamma}\left(\mathrm{cm}^{3} / \mathrm{g} . \mathrm{K}\right)$ & $0.477 \times 10^{-3}$ & {$[2]$} \\
\hline$K_{22}(\mathrm{~K})$ & 52.38 & {$[2]$} \\
\hline$a$ & 0.44 & [2] \\
\hline $\mathrm{B}^{+}$ & 0.645 & This work \\
\hline
\end{tabular}

Table S1. Values of the parameters used in the model 


\section{Nomenclature:}

$a$ : Ratio of the coefficients of thermal expansion of the polymer below and above $\mathrm{T}_{\mathrm{g}}$ of polymer $\mathrm{D}^{\circ}$ : Pre-exponential factor of monomer diffusion coefficient $\left(\mathrm{cm}^{2} / \mathrm{s}\right)$

E: Activation energy of monomer diffusion coefficient (cal/mol)

$\frac{K_{11}}{\gamma}, \frac{K_{12}}{\gamma}:$ Free volume parameters $\left(\mathrm{cm}^{3} / \mathrm{g} . \mathrm{K}\right)$

$K_{21}, K_{22}$ : Free volume parameters(K)

$k_{d}^{p o l 2}$ : Mass transfer rate coefficient of Polymer $2\left(\mathrm{~mol} / \mathrm{dm}^{2} . \mathrm{s}\right)$

$k_{p}$ : Propagation rate constant (L/mol.s)

$k_{a}$ : Rate coefficient for cluster coagulation $(L / S)$

$k_{\text {mov } 1}$ : Rate coefficient movement to non-equilibrium interior position $(1 / s)$

$k_{m o v 2^{\prime}}:$ Rate coefficient for movement to equilibrium position $(L / s)$

$k_{n}$ : Rate coefficient for nucleation $(\mathrm{mol} / \mathrm{s})$

$m 1(x)$ : Number of clusters with size $x$ at non-equilibrium exterior positions

$m 2(x)$ : Number of clusters with size $x$ at non-equilibrium interior positions

$m_{a v}$ : Average number of clusters at non-equilibrium positions per particle

$n(x)$ : Number of clusters with size $x$ at equilibrium positions

$n_{a v}$ : Average number of clusters at equilibrium position per particle

$r_{p}$ : Radius of polymer particle $(\mathrm{m})$

$r_{p}^{m}(x)$ : Polymerization rate of non-equilibrium clusters with $\mathrm{x}$ monomer units $(1 / \mathrm{s})$

$r_{p}^{n}(x)$ : Polymerization rate of equilibrium clusters with $\mathrm{x}$ monomer units $(1 / \mathrm{s})$

$r_{\text {nuc }}$ : Rate of nucleation (1/s)

$\mathrm{Tg}_{1}$ : Monomer glass transition temperature (K) 
$\mathrm{Tg}_{2}$ : Polymer glass transition temperature (K)

$\widehat{V}_{1}^{*}$ : Specific volume of monomer $\left(\mathrm{cm}^{3} / \mathrm{g}\right)$

$\widehat{V}_{2}^{*}$ : Specific volume of polymer $\left(\mathrm{cm}^{3} / \mathrm{g}\right)$

$V_{p}$ : Total volume of polymer particles (L)

$w_{2}$ : Weight fraction of polymer

$x$ : Number of polymerized monomer units

$x_{c}$ : Initial size (number of monomeric units) of the clusters formed by phase separation

$x_{\max }$ : Maximum size (number of monomeric units) of clusters

$\bar{x}_{m}$ : Average degree of polymerization of polymer 2

$\alpha_{m, n}(x)$ : Probability of coagulation of clusters with sizes higher than the average value

$\beta$ : Parameter of the diffusion constant of radicals

$£$ : Size parameter

\section{References:}

[1] B.A. Finlayson, L.T. Biegler, I.E. Grossmann, Mathematics in Chemical Engineering, Wiley-VCH Verlag GmbH \& Co. KGaA, 2006.

[2] A. Faldi, M. Tirrell, T.P. Lodge, E. Von Meerwall, Monomer Diffusion and the Kinetics of Methyl Methacrylate Radical Polymerization at Intermediate to High Conversion, Macromolecules. 27 (1994) 4184-4192.

[3] G.B. Smith, G.T. Russell, J.P.A. Heuts, Termination in dilute-solution free-radical polymerization: A composite model, Macromol Theory Simulations. 12 (2003) 299-314.

[4] J.M. Asua, S. Beuermann, M. Buback, P. Castignolles, B. Charleux, R.G. Gilbert, et al., Critically Evaluated Rate Coefficients for Free-Radical Polymerization, 5 Propagation Rate Coefficient for Butyl Acrylate, Macromol Chem Phys. 205 (2004) 2151-2160.

[5] S. Beuermann, M. Buback, Rate coefficients of free-radical polymerization deduced from pulsed laser experiments, Prog Polym Sci. 27 (2002) 191-254.

[6] M.A. Dube, A. Penlidis, K.F. O’Driscoll, A kinetic investigation of styrene/butyl acrylate copolymerization, Can J Chem Eng. 68 (1990) 974-987.

[7] S. Hamzehlou, J.R. Leiza, J.M. Asua, A new approach for mathematical modeling of the 
dynamic development of particle morphology, Chem Eng J. 304 (2016) 655-666. 